ARTICLE

DOI: $10.1038 / s 41467-018-04603-z$

OPEN

\title{
Alternative assembly of respiratory complex II connects energy stress to metabolic checkpoints
}

\author{
Ayenachew Bezawork-Geleta1,2, He Wen ${ }^{3,4}$, LanFeng Dong ${ }^{1}$, Bing Yan ${ }^{1}$, Jelena Vider (1D 1, Stepana Boukalova ${ }^{5}$, \\ Linda Krobova ${ }^{5}$, Katerina Vanova ${ }^{5}$, Renata Zobalova ${ }^{5}$, Margarita Sobol ${ }^{6}$, Pavel Hozak ${ }^{6}$, Silvia Magalhaes Novais ${ }^{5}$, \\ Veronika Caisova ${ }^{7,8}$, Pavel Abaffy ${ }^{5}$, Ravindra Naraine ${ }^{5}$, Ying Pang ${ }^{7}$, Thiri Zaw ${ }^{9}$, Ping Zhang ${ }^{1}$, Radek Sindelka ${ }^{5}$, \\ Mikael Kubista ${ }^{5,10}$, Steven Zuryn ${ }^{2}$, Mark P. Molloy ${ }^{9}$, Michael V. Berridge ${ }^{11}$, Karel Pacak ${ }^{7}$, \\ Jakub Rohlena ${ }^{5}$, Sunghyouk Park ${ }^{4} \&$ Jiri Neuzil ${ }^{1,5}$
}

Cell growth and survival depend on a delicate balance between energy production and synthesis of metabolites. Here, we provide evidence that an alternative mitochondrial complex II (CII) assembly, designated as $\mathrm{Cll}_{\text {low, }}$ serves as a checkpoint for metabolite biosynthesis under bioenergetic stress, with cells suppressing their energy utilization by modulating DNA synthesis and cell cycle progression. Depletion of $\mathrm{Cll}_{\text {low }}$ leads to an imbalance in energy utilization and metabolite synthesis, as evidenced by recovery of the de novo pyrimidine pathway and unlocking cell cycle arrest from the S-phase. In vitro experiments are further corroborated by analysis of paraganglioma tissues from patients with sporadic, SDHA and SDHB mutations. These findings suggest that $\mathrm{Cll}_{\text {low }}$ is a core complex inside mitochondria that provides homeostatic control of cellular metabolism depending on the availability of energy.

\footnotetext{
${ }^{1}$ School of Medical Sciences, Griffith University, Southport 4222 Qld, Australia. ${ }^{2}$ Clem Jones Centre for Ageing Dementia Research, Queensland Brain Institute, University of Queensland, Brisbane 4072 QId, Australia. ${ }^{3}$ Department of Biochemistry and Molecular Biology, Shenzhen University School of Medicine, Shenzhen 518060, China. ${ }^{4}$ College of Pharmacy, Natural Product Research Institute, Seoul National University, Seoul 08826, Korea. ${ }^{5}$ Institute of Biotechnology, Czech Academy of Sciences, Prague-West 25250, Czech Republic. ${ }^{6}$ Institute of Molecular Genetics, Czech Academy of Sciences, Prague 14220, Czech Republic. ${ }^{7}$ Eunice Kennedy Shriver National Institute of Child Health and Human Development, National Institutes of Health, Bethesda 20892 MD, USA. ${ }^{8}$ Faculty of Science, University of South Bohemia, Ceske Budejovice 37005, Czech Republic. ${ }^{9}$ Australian Proteome Analysis Facility, Macquarie University, North Ryde 2109 NSW, Australia. ${ }^{10}$ TATAA Biocenter, Gothenburg 41103, Sweden. ${ }^{11}$ Malaghan Institute of Medical Research, Wellington 6242, New Zealand. These authors contributed equally: Ayenachew Bezawork-Geleta, He Wen. Correspondence and requests for materials should be addressed to A.B.-G. (email: a.bezawork-geleta@griffith.edu.au) or to J.R. (email: jakub.rohlena@ibt.cas.cz) or to S.P. (email: psh@snu.ac.kr) or to J.N. (email: j.neuzil@griffith.edu.au)
} 
$\mathrm{M}$ itochondria are semi-autonomous organelles found in the majority of eukaryotic cells. They have their own genome (mitochondrial DNA, mtDNA), which encodes subunits of respiratory complexes and RNA components for mitochondrial protein synthesis. Major roles of mitochondria include generation of energy and synthesis of metabolites. Molecules that are a source of energy are oxidized in a series of biochemical reactions within the tricarboxylic acid (TCA) cycle. Intermediate products of the TCA cycle are used as signaling molecules and as building blocks for various macromolecules, while NADH and $\mathrm{FADH}_{2}$ are metabolized via oxidative phosphorylation (OXPHOS) to yield ATP. OXPHOS comprises five complexes, CI-CV. CII (succinate dehydrogenase, SDH) contains nuclear-encoded SDHA, SDHB, SDHC, and SDHD subunits, which are recognized as tumor suppressors ${ }^{1-3}$. Besides its role in OXPHOS, CII converts succinate to fumarate in the TCA cycle, and is thus at the crossroad of the TCA cycle and OXPHOS ${ }^{4}$.

Clinical data document the presence of somatic mutations in mtDNA in cancer in both the regulatory D-LOOP and the coding regions ${ }^{5-8}$. Previous research has mainly concerned the effects of mtDNA mutations on CI, CIII, CIV, and CV, with CII having been a relatively minor focus. This is explained by the fact that unlike all other OXPHOS complexes, CII does not contain mtDNA-encoded subunits, and therefore no direct effect of mtDNA defects on CII assembly and function has been expected. Further, individual respiratory complexes form supercomplexes $(\mathrm{SCs})^{9-11}$, while CII acts as a stand-alone complex, with only one report indicating that it can be an SC component ${ }^{12}$.

This study investigates whether CII subunits and mtDNA could have any form of interaction in energy production, and if so, whether there is a functional relation that provides an advantage to cells with mtDNA mutations. We show that depletion of mtDNA has an unexpected effect on CII assembly, causing a shift from its tetrameric, fully processed, and assembled form to a slower migrating complex of $\sim 100 \mathrm{kDa}$, referred to here as complex $\mathrm{II}_{\text {low }}\left(\mathrm{Cll}_{\text {low }}\right)$. Our data suggest that $\mathrm{CII}_{\text {low }}$ links bioenergetic stress to negative regulation of de novo pyrimidine synthesis and cell cycle progression, which is supported by clinical data from paraganglioma patients with mutations in $\mathrm{SDH}$ subunits, indicating that $\mathrm{Cl}_{\text {low }}$ plays an important role in homeostatic control of metabolite synthesis under bioenergetic stress.

\section{Results}

mtDNA-linked bioenergetics defects affect the assembly of CII. Unlike other respiratory complexes, CII is encoded by nuclear DNA and is genetically independent of mtDNA. To understand if mtDNA dysfunction affects CII indirectly, we tested the effect of mtDNA perturbation ${ }^{8,13-15}$ on CII assembly. Native blue gel electrophoresis (NBGE) of mitochondria isolated from murine 4T1 and human MCF7 cells without mtDNA ( $\rho^{0}$ cells) revealed that CII exists in two hetero-oligomeric forms of $\sim 100 \mathrm{kDa}$ and $124 \mathrm{kDa}$ (migrating on NBGE at $\sim 140 \mathrm{kDa}$ ). In $4 \mathrm{~T} 1 \rho^{0}$ and MCF7 $\rho^{0}$ cells, SDHA was mainly present as $\mathrm{CII}_{\text {low }}$, with no known biological function reported to date, and to a lesser degree within fully assembled CII (Fig. 1a). The finding of predominant $\mathrm{CII}_{\text {low }}$ in $4 \mathrm{~T} 1 \rho^{0}$ and MCF7 $\rho^{0}$ cells suggests that this form of CII may have a role in (patho)physiological situations where mtDNA is damaged. The size of the processed SDHA protein is $\sim 69 \mathrm{kDa}$, while $\mathrm{CII}_{\text {low }}$ migrates on native gels at $\sim 100 \mathrm{kDa}$. Hence, additional protein components beyond SDHA must be present in $\mathrm{CII}_{\text {low. }}$.

We next examined CII assembly in human MDA-MB-231 (MDA231) cells. Inhibition of mitochondrial protein synthesis with chloramphenicol (CAB), a blocker of mitochondrial translation ${ }^{16-18}$, resulted in depletion of CIII and SCs (Fig. 1b, right panels). Similarly, as with $4 \mathrm{~T} 1 \rho^{0}$ and $\mathrm{MCF} \rho^{0}$ cells, CABtreated MDA231 cells accumulated $\mathrm{CII}_{\text {low }}$ containing SDHA (Fig. 1b, left panels), suggesting that this form of CII may have (patho)physiological relevance when expression of mtDNAencoded proteins is compromised.

SDHA is a stable constituent of $\mathrm{CII}_{\text {low }}$. To better characterize the subunit composition of $\mathrm{CII}_{\text {low }}$, SDHA, SDHB, and SDHC subunits were knocked down one at a time in $4 \mathrm{~T} 1$ cells using two different siRNAs (siRNA1 and siRNA2), and CII assembly state was followed by NBGE. Depletion of any of the three subunits reduced the level of CII. Interestingly, only the knockdown of SDHA, but not of the other CII subunits, resulted in marked reduction of $\mathrm{CII}_{\text {low }}$ (Fig. 1c and d), corroborating the presence of SDHA, but not SDHB or SDHC, in $\mathrm{CII}_{\text {low }}$.

The identification of SDHA in $\mathrm{CII}_{\text {low }}$ suggests that it may be more stable than the other CII subunits. We therefore examined the steady state of each subunit in our knockdown cell lines. Depletion of SDHB led to a decrease in the steady state of SDHC, and knockdown of SDHC led to a decrease in the steady state of SDHB. Interestingly, in SDHA knockdown cells, both SDHB and SDHC levels decreased by $\sim 70 \%$. Knocking down either SDHB or SDHC had no effect on the steady state of SDHA (Fig. 1e). It is likely that depletion of SDHA leads to low levels of SDHB and SDHC, probably due to low stability of unassembled subunits as indicated previously ${ }^{19-21}$.

Characterization of the $\mathrm{CII}_{\text {low }}$ form of SDH. Based on crystal structure of $\mathrm{CII}^{22}$ (Supplementary Fig. 1a) and our data in Fig. 1e, we hypothesized that depletion of SDHB will result in cells containing only $\mathrm{CII}_{\text {low. }}$. We thus generated SDHB knockout (KO) MDA231 cells targeting exon 1 (Fig. 2a and b). As with $4 \mathrm{~T} 1$ cells (Fig. 1c and e), the steady-state level of SDHA was unchanged in $\mathrm{SDHB}^{\mathrm{KO}}$ MDA231 cells (Fig. 2c). In order to deplete $\mathrm{CII}_{\text {low }}$, $\mathrm{SDHB}^{\mathrm{KO}}$ MDA231 cells were transfected with two different

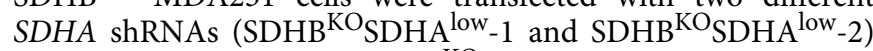
and an empty vector $\left(\mathrm{SDHB}^{\mathrm{KO}} \mathrm{EV}\right)$ as a control (Fig. 2c; Supplementary Fig. 1b). NBGE analysis showed high levels of $\mathrm{CII}_{\text {low }}$ in $\mathrm{SDHB}^{\mathrm{KO}} \mathrm{MDA} 231$ cells and little $\mathrm{CII}_{\text {low }}$ in $\mathrm{SDHB}^{\mathrm{KO}} \mathrm{SDHA}{ }^{\text {low }}$ cells (Fig. $2 \mathrm{~d}$ ). We thus prepared models of cells with three variants of CII assembly: fully assembled CII and low levels of $\mathrm{CII}_{\text {low }}$ (parental cells), cells with only $\mathrm{CII}_{\text {low }}$ $\left(\mathrm{SDHB}^{\mathrm{KO}} \mathrm{SDHB}^{\mathrm{KO}} \mathrm{EV}\right.$ cells), and cells lacking both $\mathrm{CII}$ and $\mathrm{CII}_{\text {low }}$ (SDHB ${ }^{\mathrm{KO}} \mathrm{SDHA}{ }^{\text {low }}$ cells). These models showed low proliferation for both $\mathrm{SDHB}^{\mathrm{KO}}$ and $\mathrm{SDHB}^{\mathrm{KO}} \mathrm{SDHA}{ }^{\text {low }}$ cells (Fig. 2e).

To specify its molecular composition, we transfected $\mathrm{SDHB} \mathrm{KO}^{\mathrm{KO}}$ cells with SDHA-FLAG and immunoprecipitated the cell-free extract using anti-FLAG IgG. The immunoprecipitate was subjected to tryptic digest followed by MS analysis (Supplementary Fig. 2a), with results of the screen in Supplementary Fig. 2a and Supplementary Data 1 . The analysis revealed the presence of the CII assembly factors SDHAF2 $(16.7 \mathrm{kDa})$ and SDHAF4 $(9.9$ $\mathrm{kDa}$ ). While SDHAF2 was readily detectable on NBGE membranes in $\mathrm{CII}_{\text {low }}$ (Supplementary Fig. 2b), the available antibodies did not allow reproducible detection of SDHAF4 after NBGE, and its presence was verified by other means (see below).

We next re-expressed SDHB-FLAG in SDHB ${ }^{\mathrm{KO}}$ cells to see whether this would rescue the parental phenotype and whether $\mathrm{CII}_{\text {low }}$ is reversible. SDHB-reconstituted (SDHB ${ }^{\text {rec }}$ ) cells were assessed by Western blotting (WB) following SDS-PAGE for the presence of SDHA, SDHB, SDHAF2, and SDHAF4. Supplementary Fig. 2c documents similar levels of SDHA in all three sublines and high levels of SDHB in parental and $\mathrm{SDHB}^{\text {rec }}$ cells. In contrast, both SDHAF2 and SDHAF4 were low in parental and 
a

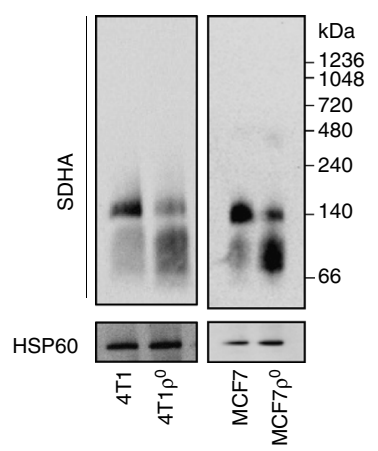

C

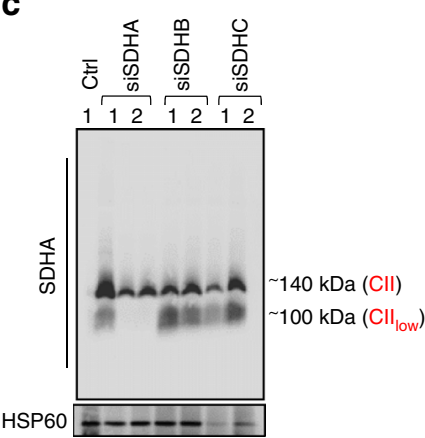

e

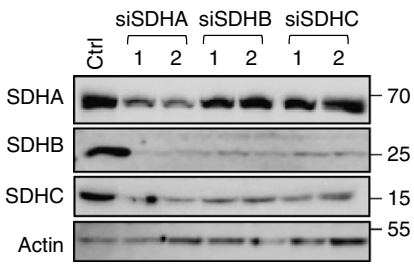

b

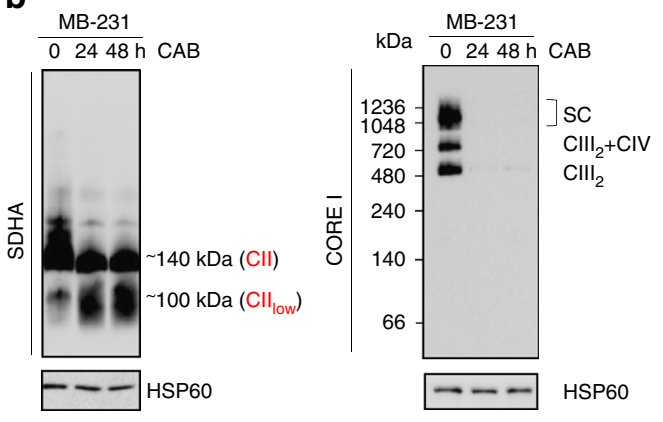

d
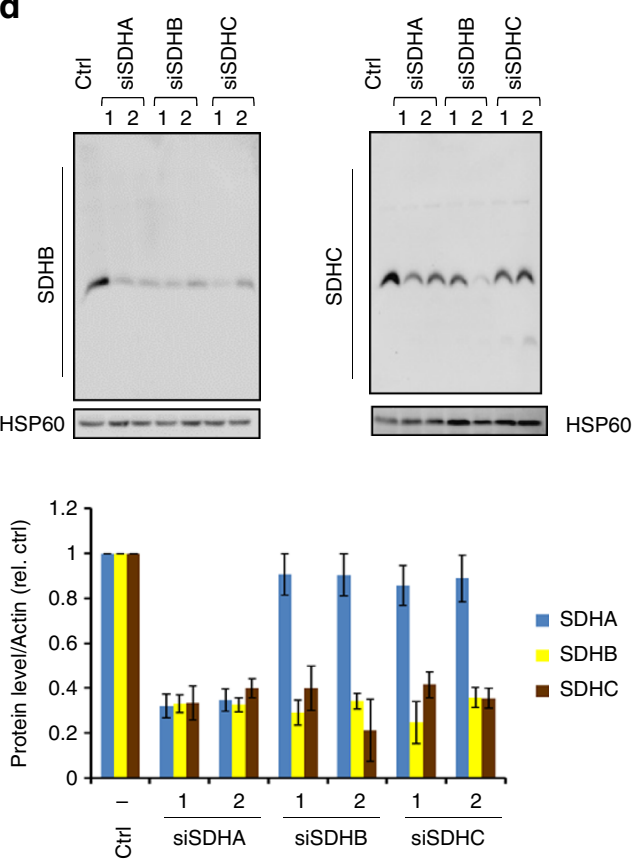

Fig. 1 mtDNA dysfunction affects CII assembly. a NBGE analyses of Cll assembly from digitonin-solubilized mitochondria isolated from 4T1 and MCF7 cells and their $\rho^{0}$ counterparts. $\mathbf{b}$ NBGE showing formation of $\mathrm{Cll}_{\text {low }}$ and depletion of $\mathrm{CIII}$ assembly upon suppression of expression of mtDNA-encoded genes with $C A B$ at indicated time points. c, d NBGE of CIl using mitochondria isolated from 4T1 cells transfected with siRNA against SDHA, SDHB, or SDHC. e WB after SDS-PAGE of steady-state levels of CIl subunits in $4 T 1$ cells treated with siRNAs as shown (left panel). Right panel shows quantification of WB in the left panel related to actin. The numbers ' 1 ' and ' 2 ' in $\mathbf{c}$-e refer to two different siRNAs. Data shown are mean values \pm SD; images are representative of three independent experiments

$\mathrm{SHDB}^{\mathrm{rec}}$ cells, but accumulated in $\mathrm{SDHB}^{\mathrm{KO}}$ cells. We then tested the three sublines by NBGE followed by WB using anti-SDHA IgG and anti-SDHAF2 IgG. Supplementary Fig. 2d reveals that mature $\mathrm{CII}$ is re-assembled and the amount of $\mathrm{CII}_{\text {low }}$ reverts to parental levels in $\mathrm{SDHB}^{\text {rec }}$ cells, indicating SDHB-dependent reversibility of alternatively assembled CII. Furthermore, SDHAF2 and SDHAF4 were detectable only in SDHB ${ }^{\mathrm{KO}}$ cells that lack mature CII but feature $\mathrm{CII}_{\text {low }}$, supporting the presence of these assembly factors in $\mathrm{CII}_{\text {low }}$ cells.

To verify the reversibility of $\mathrm{CII}_{\text {low }}$ in response to stress, we treated parental cells with $\mathrm{CAB}$ for $48 \mathrm{~h}$, followed by $24 \mathrm{~h}$ recovery. The amount of $\mathrm{CII}_{\text {low }}$ was evaluated by NBGE using antibodies against SDHA and SDHAF2, two $\mathrm{CII}_{\text {low }}$ components readily detectable in this assay (Supplementary Fig. 2e). Treatment with $\mathrm{CAB}$ increased the level of $\mathrm{CII}_{\text {low, }}$, which reverted to baseline within $24 \mathrm{~h}$ of treatment cessation. Together with the $\mathrm{SDHB}^{\text {rec }}$ data, this indicates reversibility of $\mathrm{CII}_{\text {low }}$ assembly, providing flexibility in response to mitochondrial bioenergetic stress.
$\mathrm{CII}_{\text {low }}$ does not modulate mitochondrial bioenergetics. We asked whether altered assembly of SDHA affects mitochondrial bioenergetics as well as expression and assembly of other mitochondrial complexes. We found that basal respiration, maximum respiratory capacity, and ATP production were decreased both in $\mathrm{SDHB}^{\mathrm{KO}} \mathrm{EV}$ and $\mathrm{SDHB}^{\mathrm{KO}} \mathrm{SDHA}^{\text {low }}$ cells (Fig. 3a-e). Unlike parental cells, absence of spare respiratory capacity and low ATP production were found in $\mathrm{SDHB}^{\mathrm{KO}} \mathrm{EV}$ and $\mathrm{SDHB}^{\mathrm{KO}} \mathrm{SDHA}{ }^{\text {low }}$ cells (Fig. 3d, e), further indicating a state of bioenergetic stress. We next assessed oxygen consumption in permeabilized MDA231 cells by high-resolution respirometry. This showed that alteration of the CII assembly status resulted not only in complete suppression of CII-dependent respiration, but also considerably altered CI-dependent respiration (Fig. 3f). Consistent with the above results, we found that assembly of SCs was reduced in $\mathrm{SDHB}^{\mathrm{KO}}$ and $\mathrm{SDHB}^{\mathrm{KO}} \mathrm{SDHA}^{\text {low }}$ cells (Fig. 3g). This is further supported by lower steady-state levels of CI subunits but not CIII, $\mathrm{CIV}$, and $\mathrm{CV}$ subunits (Fig. 3h). However, there was no significant difference between $\mathrm{SDHB}^{\mathrm{KO}}$ and $\mathrm{SDHB}^{\mathrm{KO}} \mathrm{SDHA}^{\text {low }}$ cells 
a
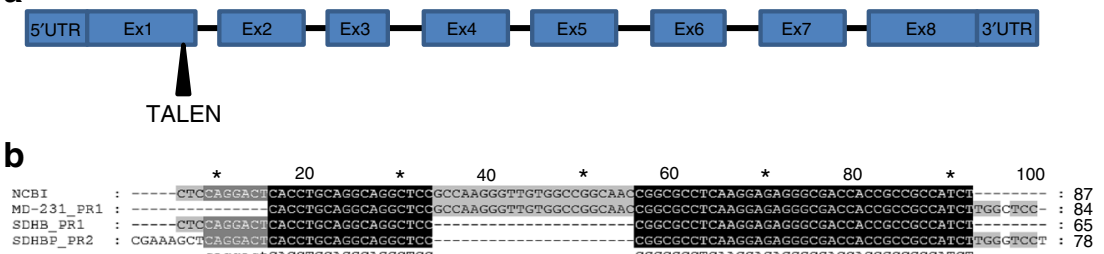

C

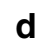

d

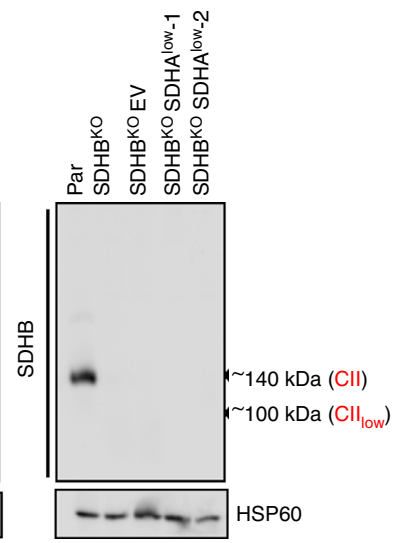

e

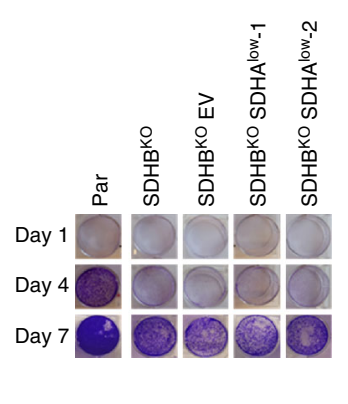

Fig. 2 SDHB depletion stabilizes $\mathrm{Cll}_{\text {low. }}$ a A scheme showing the structure of the SDHB gene and exon1 as the TALEN target. $\mathbf{b}$ DNA sequence alignment of the SDHB exon 1 from the GenBank nucleotide sequence database, and parental and SDHB KO MDA231 cells. Sanger sequencing was done from the PCR product amplified using two pairs of primers (PR1 and PR2) using genomic DNA as a template. c WB after SDS-PAGE of CII subunits in individual sublines, as shown. $\mathrm{SDHB}^{\mathrm{KO}} \mathrm{EV}$ cells are $\mathrm{SDHB} \mathrm{B}^{\mathrm{KO}}$ cells transfected with empty vector and were used as a control for stable shRNA transfections. $\mathbf{d}$ NBGE of mitochondria isolated from parental, $\mathrm{SDHB}{ }^{\mathrm{KO}}, \mathrm{SDHB}{ }^{\mathrm{KO}} \mathrm{EV}$, and $\mathrm{SDHB}{ }^{\mathrm{KO}} \mathrm{SDH} \mathrm{A}^{\text {low }}$ cells showing three variants of SDHA, using anti-SDHA IgG and antiSDHB IgG. e Proliferation of MDA231 subline was analyzed at the indicated time points using the crystal violet method. Panel on the right shows crystal violet staining at 1, 4, and 7 days. Data are normalized to day 1. Data shown are mean values \pm SD $(n=3)$; images are representative of three independent experiments

for any of the assessed parameters. In contrast, re-expression of SDHB-FLAG (SDHB ${ }^{\text {rec }}$ cells) substantially recovered the parental phenotype with respect to routine and CII-dependent respiration (Supplementary Fig. S2f).

Cells with severe defects in OXPHOS rely on glycolysis for ATP production and do not grow in the presence of galactose $\mathrm{e}^{23}$. We tested proliferation of MDA231 sublines in galactose- and glucose-containing media, and found that both $\mathrm{SDHB}^{\mathrm{KO}} \mathrm{EV}$ and $\mathrm{SDHB}^{\mathrm{KO}} \mathrm{SDHA}^{\text {low }}$ cells failed to proliferate in galactosecontaining medium whereas parental cells proliferated efficiently (Fig. 3i). This is in agreement with previous reports on cells with defects in CI and CII assembly ${ }^{23-26}$. Again, re-expressed SDHB rescued proliferation in galactose-containing media (Supplementary Fig. 2g).

Similarly, analysis of mitochondrial morphology using transmission electron microscopy (TEM) revealed that both $\mathrm{SDHB}^{\mathrm{KO}} \mathrm{EV}$ and $\mathrm{SDHB}^{\mathrm{KO}} \mathrm{SDHA}^{\text {low }}$ cells featured mitochondria with altered structure (Supplementary Fig. 3a), consistent with a previous report ${ }^{27}$. These changes did not affect the steady-state level of several key proteins associated with mitochondrial maintenance and biogenesis (Supplementary Fig. 3b). Thus, while CII assembly status affected whole-cell bioenergetics and proliferation, $\mathrm{CII}_{\text {low }}$ had little additional effect on mitochondrial bioenergetics and biogenesis.

Pyrimidine synthesis is attenuated in the presence of $\mathrm{CII}_{\text {low }}$. Having found no direct effect on bioenergetics, we reasoned that $\mathrm{CII}_{\text {low }}$ could modulate adaptation to altered bioenergetic conditions. Thus, we first performed quantitative proteomic analysis in MDA231 sublines using SWATH-MS ${ }^{28}$ that resulted in identification and quantification of 1699 individual proteins (Supplementary Data 2). The most downregulated pathway in $\mathrm{SDHB}^{\mathrm{KO}} \mathrm{EV}$ cells compared to parental cells was de novo pyrimidine synthesis (Fig. 4a). Quantification of the SWATH-MS data revealed that this downregulation is reversed in $\mathrm{SDHB}^{\mathrm{KO}} \mathrm{SDHA}^{\text {low }}$ cells (Supplementary Fig. 4), indicating that $\mathrm{SDHB}^{\mathrm{KO}}$ cells may suppress anabolic processes to reduce the energy demand, and this is then relieved in $\mathrm{SDHB}^{\mathrm{KO}} \mathrm{SDHA}^{\text {low }}$ cells. To further investigate this issue, we subjected parental, $\mathrm{SDHB}^{\mathrm{KO}}$, and $\mathrm{SDHB}^{\mathrm{K} 8} \mathrm{SDHA}^{\text {low }}$ cells to RNAseq analysis (Supplementary Fig. 5a and b), which revealed significant clusters 
a

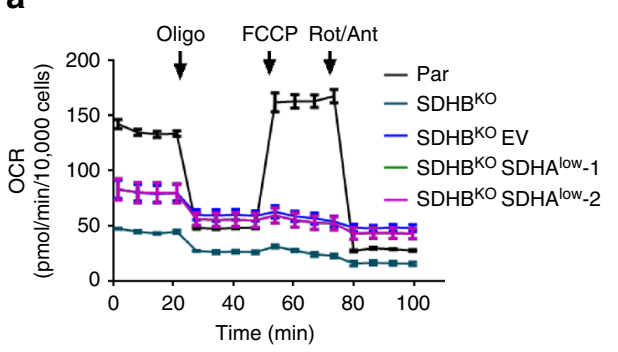

b

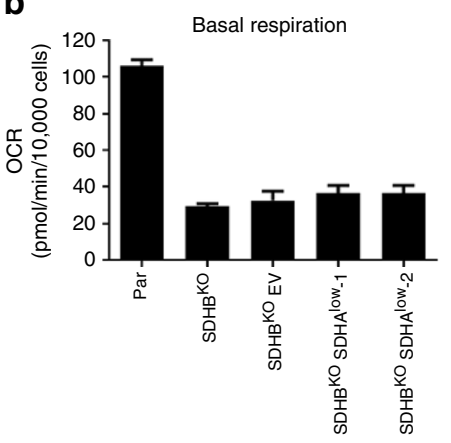

c

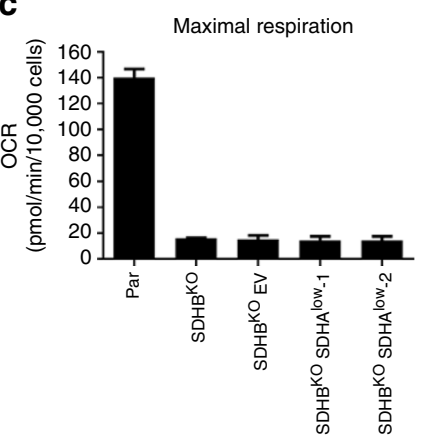

d

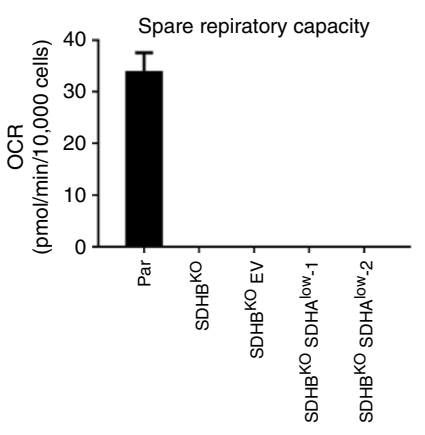

g

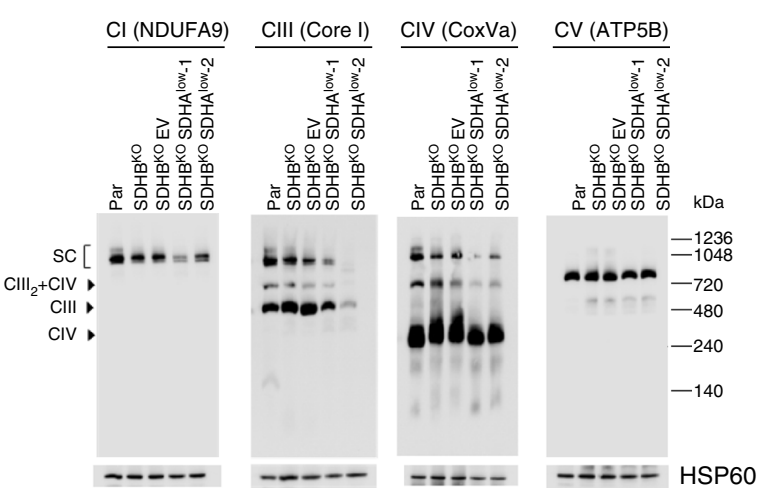

e

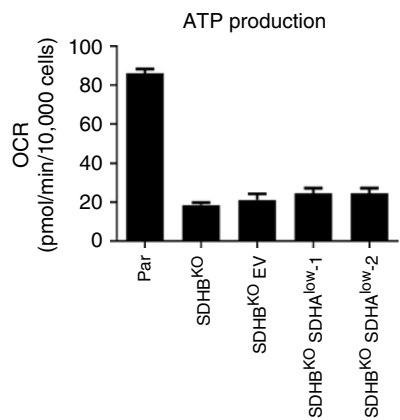

f

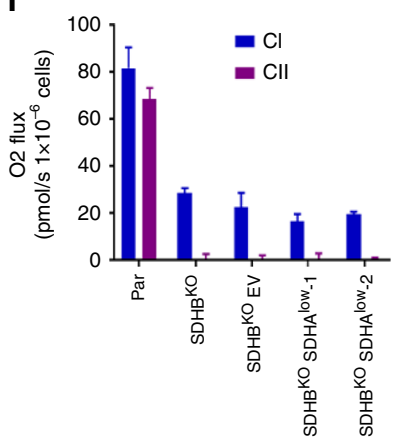

h

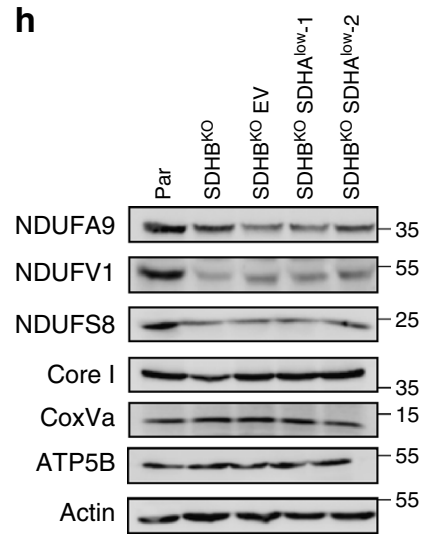

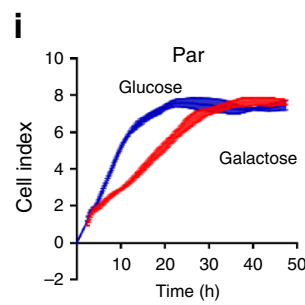
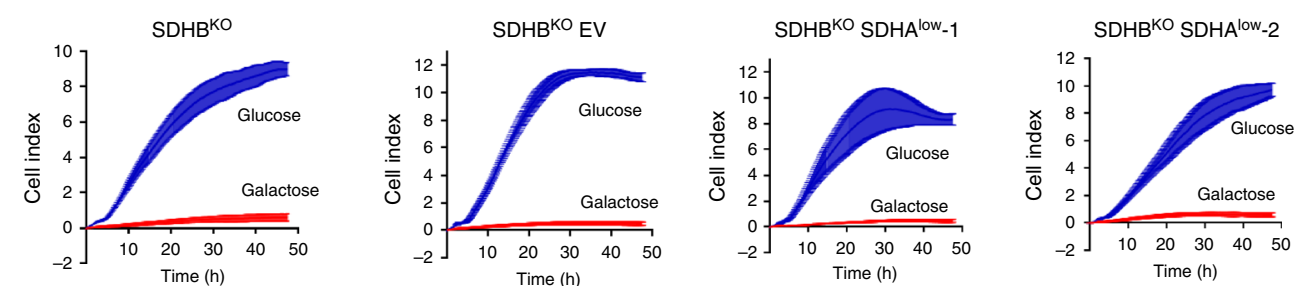

Fig. $3 \mathrm{Cll}_{\mathrm{low}}$ does not regulate mitochondial bioenergetics. a Oxygen consumption rate (OCR) in MDA231 sublines was followed during sequential additions of oligomycin, FCCP, and combination with rotenone and antimycin. b-e Basal respiration, maximal respiration, spare respiratory capacity, and ATP production. $\mathbf{f ~ C l - ~ a n d ~ C l l - d e p e n d e n t ~ r e s p i r a t i o n ~ w a s ~ e v a l u a t e d ~ i n ~ p e r m e a b i l i z e d ~ c e l l s ~ u s i n g ~ t h e ~ O x y g r a p h . ~} \mathbf{g}$ Mitochondria isolated from MDA231 sublines were subjected to NBGE followed by WB analysis using antibodies against NDUFA9, NDUFV1, NDUFS8 (CI), Core I (CIII), and COXVa (CIV) and ATP5B (CV). h MDA231 sublines were analyzed for subunits of OXOPHOS complexes using WB after SDS-PAGE. i MDA231 sublines grown in media containing either glucose or galactose were evaluated for proliferation using the $\mathrm{xCELLingence} \mathrm{instrument.} \mathrm{Data} \mathrm{shown} \mathrm{are} \mathrm{mean} \mathrm{values} \pm$ SD ( $n=$ 3); images and graphs in $\mathbf{i}$ are representative of three independent experiments

of genes either upregulated or downregulated in $\mathrm{SDHB}^{\mathrm{KO}}$ cells with expression being reverted toward parental cell levels in $\mathrm{SDHB}^{\mathrm{KO}} \mathrm{SDHA}^{\text {low }}$ cells (Groups 1 and 2 in Supplementary Fig. 5b-f). Gene set enrichment analysis revealed the presence of catabolism-related processes in these clusters, including heterocycle catabolic process (GO:0046700), aromatic compound catabolic process (GO:0019439), organic cyclic compound catabolic process (GO:1901361), and cellular macromolecule catabolic process (GO:0044265) that were all downregulated in $\mathrm{SDHB}^{\mathrm{KO}} \mathrm{SDHA}{ }^{\text {low }}$ cells compared to SDHB ${ }^{\mathrm{KO}}$ cells (Supplementary Fig. 5e and f). However, the de novo pyrimidine synthesis pathway did not show significant enrichment, pointing 
to modest correlation of transcriptomic and proteomic data as previously reported ${ }^{29-33}$. Collectively, these data suggest that $\mathrm{SDHB}^{\mathrm{KO}}$ cells may upregulate catabolic and salvage pathways to compensate for defects in pyrimidine biosynthesis.
We next focused our studies on pyrimidine biosynthesis. Initially, we evaluated representative proteins of this pathway using $\mathrm{WB}$, and found that the trifunctional polypeptide CAD (carbamoyl-phosphate synthase 2, aspartate transcarbamylase, a

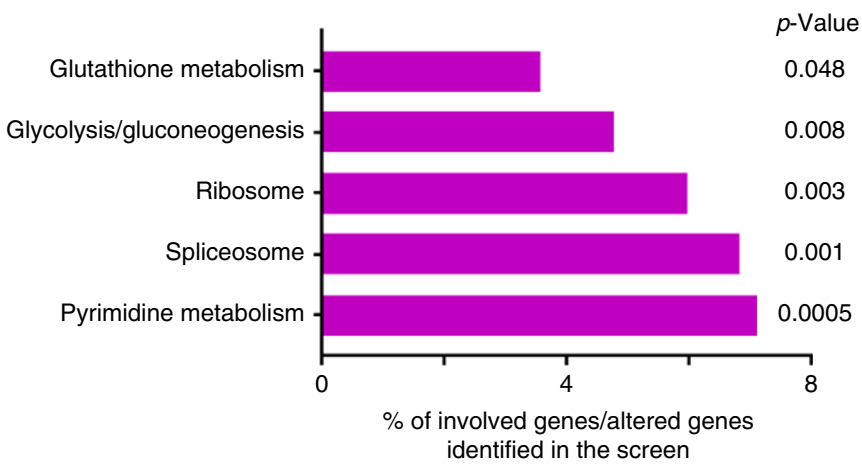

b

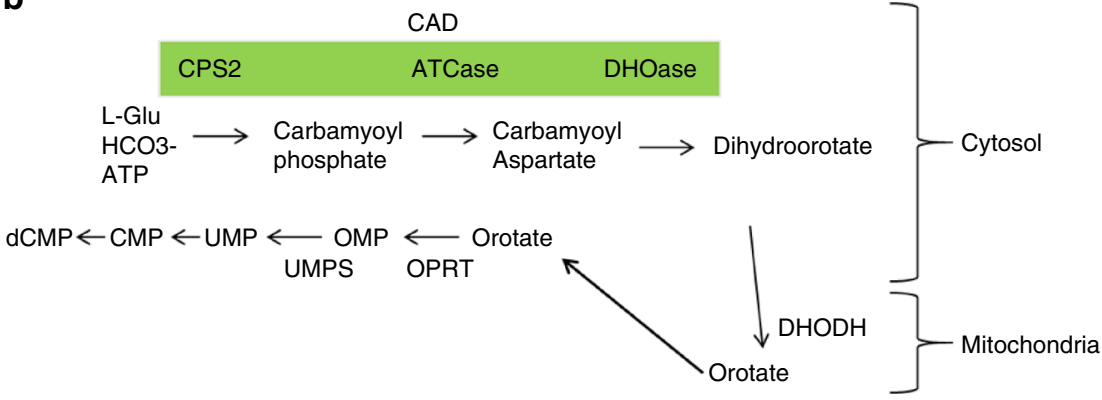

C

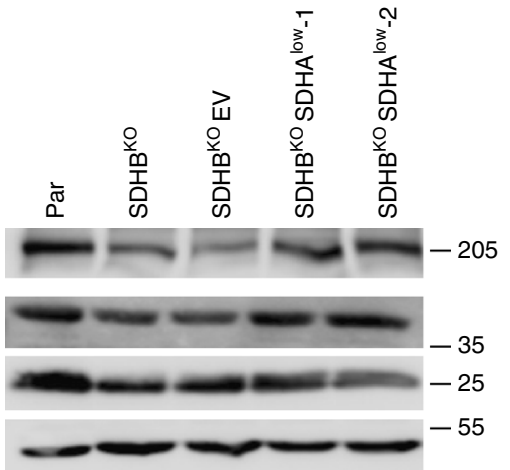

d

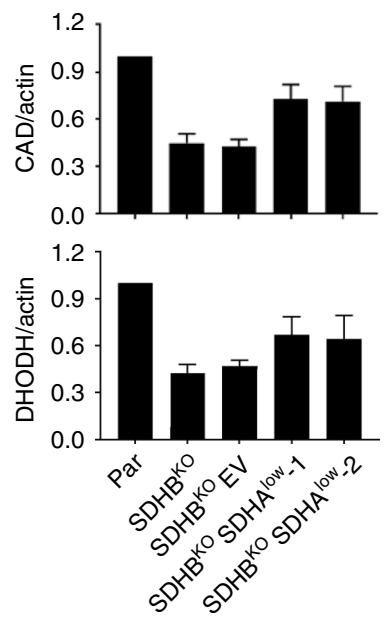

e

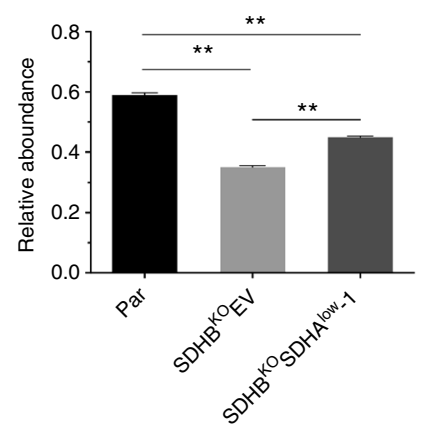

f

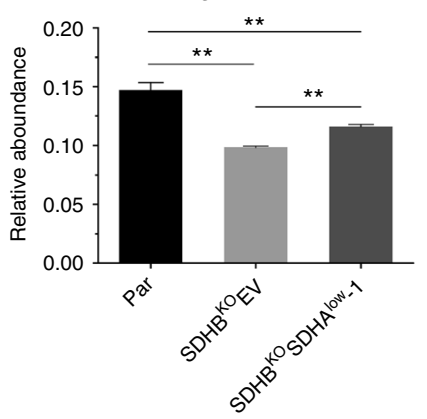

$\left[\mathrm{U}-{ }^{13} \mathrm{C}\right]$-glucose $\rightarrow \mathrm{CDP}$

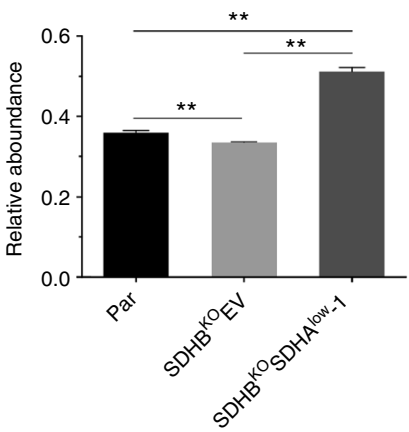

$\left[\mathrm{U}-{ }^{13} \mathrm{C}\right]$-glutamine $\rightarrow \mathrm{CDP}$

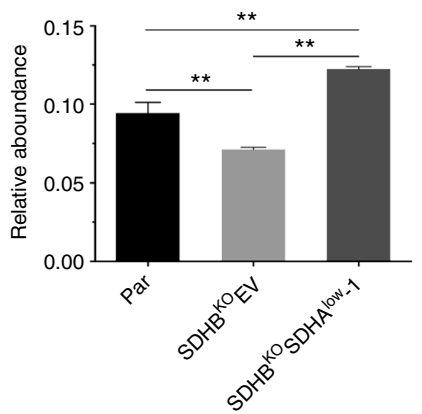

$\left[\mathrm{U}-{ }^{13} \mathrm{C}\right]$-glucose $\rightarrow$ UTP

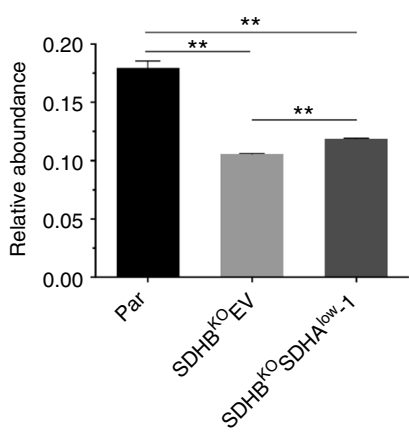

$\left[\mathrm{U}-{ }^{13} \mathrm{C}\right]$-glutamine $\rightarrow$ UTP

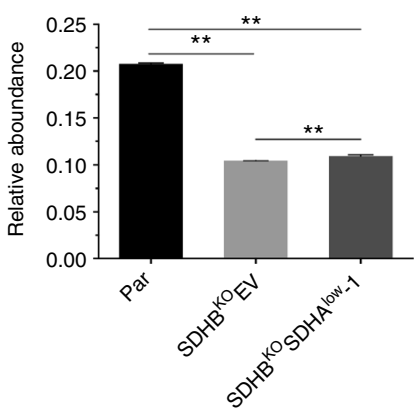

$\left[\mathrm{U}-{ }^{13} \mathrm{C}\right]$-glucose $\rightarrow$ UDP

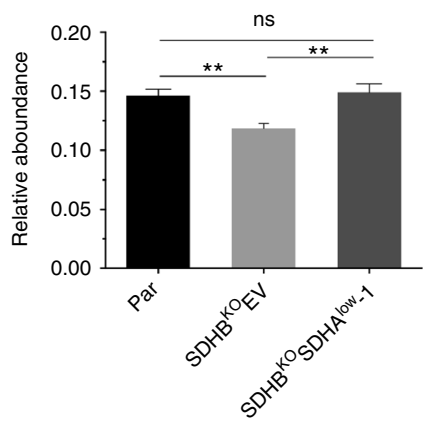

$\left[\mathrm{U}-{ }^{13} \mathrm{C}\right]$-glutamine $\rightarrow$ UDP

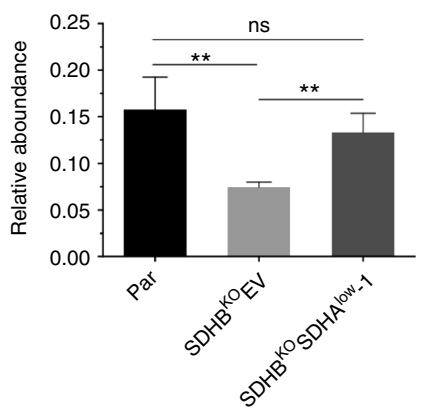


and dihydroorotase) and dihydroorotate dehydrogenase (DHODH) that catalyze the first four steps of de novo pyrimidine synthesis were attenuated in $\mathrm{SDHB}^{\mathrm{KO}} \mathrm{EV}$ but recovered in $\mathrm{SDHB}^{\mathrm{KO}} \mathrm{SDHA}{ }^{\text {low }}$ cells (Fig. $4 \mathrm{~b}-\mathrm{d}$ ). Re-expression of SDHB in $\mathrm{SDHB}^{\mathrm{KO}}$ cells also restored CAD and DHODH (Supplementary Fig. 2h).

We then analyzed pyrimidine nucleotide synthesis directly using stable isotope labeling and LC-MS/MS. The data in Fig. 4e and f, and Supplementary Fig. 7, show that biosynthesis of CTP, CDP, UTP, and UDP from major nutrients glucose and glutamine was low in $\mathrm{SDHB}^{\mathrm{KO}} \mathrm{EV}$ cells but reversed variably in $\mathrm{SDHB}^{\mathrm{KO}} \mathrm{SDHA}{ }^{\text {low }}$ cells. These results document that compared to the baseline situation (fully assembled CII), formation of $\mathrm{CII}_{\text {low }}$ is linked to depressed de novo pyrimidine synthesis, which is reversed with its depletion. The data suggest that under lowenergy conditions, $\mathrm{CII}_{\mathrm{low}}$ may activate cellular processes reducing ATP-consuming pathways such as DNA synthesis to maintain energy balance, which is deregulated in $\mathrm{SDHB}^{\mathrm{KO}} \mathrm{SDHA}^{\text {low }}$ cells.

$\mathrm{CII}_{\text {low }}$ plays a role in cell cycle progression. De novo pyrimidine synthesis is essential for maintaining the nucleotide pool for replication of DNA, thereby controlling cell cycle progression ${ }^{34-}$ 37. We thus analyzed cell cycle distribution in MDA231 sublines, which showed that $\mathrm{SDHB}{ }^{\mathrm{KO}}$ and $\mathrm{SDHB}^{\mathrm{KO}} \mathrm{EV}$ cells were arrested in the S-phase. However, $\mathrm{SDHB}^{\mathrm{KO}} \mathrm{SDHA}^{\text {low }}$ cells partially recovered from S-phase arrest with cell cycle distribution similar to that of parental cells (Fig. 5a and b). Cell cycle is regulated by cyclins and cyclin-dependent kinases (CDKs). WB confirmed a marked decrease in the level of CDK6 as well as p16, phosphorylated histone $\mathrm{H} 3(\mathrm{HH} 3)$, and $\mathrm{CMYC}$ in $\mathrm{SDHB}^{\mathrm{KO}}$ and $\mathrm{SDHB}^{\mathrm{KO}}{ }^{\mathrm{SDH}} \mathrm{A}^{\text {low }}$ cells compared to parental cells (Fig. $5 \mathrm{c}$ ). Interestingly, $\mathrm{p} 18$ was downregulated in $\mathrm{SDHB}^{\mathrm{KO}}$ and $\mathrm{SDHB}^{\mathrm{KO}} \mathrm{EV}$ cells and recovered in $\mathrm{SDHB}^{\mathrm{KO}} \mathrm{SDHA}^{\text {low }}$ cells (Fig. 5c), similar to that seen for steady-state levels of CAD and DHODH and for nucleotide synthesis (Fig. 4). Further, we observed near parental levels of pHH3 in SDHB rec cells (Supplementary Fig. $2 \mathrm{~h}$ ). This result suggests that alteration in SDHA assembly status affects de novo pyrimidine synthesis, and consequently cell cycle progression. Our data suggest that under lowenergy conditions, the shift of $\mathrm{CII}$ to $\mathrm{CII}_{\text {low }}$ is associated with a switch to bioenergetically less-demanding processes.

$\mathrm{CII}_{\text {low }}$ supports growth of SDHB-deficient tumors. Figure $2 \mathrm{e}$ reveals no difference in proliferation between $\mathrm{SDHB}^{\mathrm{KO}} \mathrm{EV}$ and $\mathrm{SDHB}^{\mathrm{KO}} \mathrm{SDHA} \mathrm{A}^{\text {low }}$ cells, suggesting that $\mathrm{CII}_{\text {low }}$ is not critical for proliferation under nutrient-rich conditions. However, imbalance of energy production and anabolic metabolism such as that linked to DNA synthesis could be critical for biomass production required for growth and survival under sub-optimal conditions ${ }^{38}$. To see whether $\mathrm{CII}_{\text {low }}$ is important for the tumorigenic potential of MDA231 sublines, migration of parental, $\mathrm{SDHB}{ }^{\mathrm{KO}} \mathrm{EV}$, and $\mathrm{SDHB}^{\mathrm{KO}}$ SDHA ${ }^{\text {low }}$ cells was tested. Contrary to the cell proliferation assay (Fig. 2e), $\mathrm{SDHB}^{\mathrm{KO}}{ }^{\mathrm{SDH}}{ }^{\text {low }}$ cells showed a lower rate of migration from serum-free media compared to both parental and $\mathrm{SDHB}^{\mathrm{KO}}$ EV cells (Fig. 5d). To extend these results to a pathologically relevant situation, we tested the capacity of the sublines to form tumors. Parental, SDHB ${ }^{\mathrm{KO}} \mathrm{EV}$, and $\mathrm{SDHB}^{\mathrm{KO}} \mathrm{SDHA} \mathrm{A}^{\text {low }}$ cells were grafted subcutaneously into Balb-c $\mathrm{nu} / \mathrm{nu}$ mice, and tumor progression was analyzed by ultrasound imaging (USI). Compared to parental cells, $\mathrm{SDHB}^{\mathrm{KO}} \mathrm{EV}$ cells formed tumors with a delay of about 15 days and at lower rate, while $\mathrm{SDHB}^{\mathrm{KO}} \mathrm{SDHA}^{\text {low }}$ cells failed to form tumors 60 days post grafting (Fig. 5e and f). To understand whether the inability of $\mathrm{SDHB}^{\mathrm{KO}} \mathrm{SDHA}{ }^{\text {low }}$ cells to form tumors is linked to their higher vulnerability under nutrient-poor conditions, we evaluated the level of cell death in individual sublines grown in galactose media. Supplementary Fig. $3 c$, d shows that all sublines are mostly viable in glucose-containing media, while $\mathrm{SDHB}^{\mathrm{KO}}$ SDHA ${ }^{\text {low }}$ cells are more vulnerable to cell death than $\mathrm{SDHB}^{\mathrm{KO}}$ cells in non-permissive, galactose-containing media. These data point to a link between $\mathrm{CII}_{\text {low }}$ and energy balance regulation to maintain cellular fitness under nutrient-poor conditions.

$\mathrm{CII}_{\text {low }}$ modulates the metabolome. In order to better understand metabolic consequences of alternative SDHA assembly, we examined the metabolic profiles of MDA231 sublines. Metabolomic data obtained by one-dimensional (1D) nuclear magnetic resonance (NMR) were combined with additional 16 metabolites, measured using targeted LC-MS/MS that are important in central energy metabolism but are not readily quantifiable by NMR (Supplementary Data 3). Results of this analysis, represented by the heat map in Fig. 6a, indicate an effect of $\mathrm{CII}_{\text {low }}$ on the differential metabolite profile in MDA231 sublines. The data show that the metabolic profile of SDHB ${ }^{\mathrm{KO}} \mathrm{EV}$ cells has very little overlap with that of the parental cells, whereas SDHB ${ }^{\mathrm{KO}} \mathrm{SDHA} \mathrm{A}^{\text {low }}$ cells have significantly more overlap. This is consistent with partial least square discriminant analysis (PLS-DA) of the metabolomic data showing the metabolic differences between sublines and the closer position of the $\mathrm{SDHB}^{\mathrm{KO}} \mathrm{SDHA}{ }^{\text {low }}$ cells to parental cells along the PLS1 axis (Fig. 6b). Taken together with the results in Fig. 1 which demonstrated $\mathrm{CII}_{\text {low }}$ formation during OXPHOS dysfunction, these data suggest that $\mathrm{CII}_{\text {low }}$ is linked to metabolic modulation when bioenergetics is compromised.

Depletion of $\mathrm{CII}_{\mathrm{low}}$ reverses accumulation of succinate. Given the role of SDHA in the TCA cycle, we expect that $\mathrm{CII}_{\text {low }}$ could affect succinate metabolism and TCA cycle activity. We therefore subjected parental, $\mathrm{SDHB}{ }^{\mathrm{KO}} \mathrm{EV}$, and $\mathrm{SDHB}^{\mathrm{KO}} \mathrm{SDHA}^{\text {low }}$ cells to two-dimensional (2D) in-cell NMR analysis, which allows monitoring of metabolites in live cells in real time ${ }^{39}$. The approach detects metabolite levels as a function of time, as opposed to steady-state levels at a single time-point as reported above and in most metabolomics studies. This facilitates estimation of actual activities of metabolic pathways leading to particular metabolites in live cells. Thus, cells were incubated with $\left[\mathrm{U}_{-}{ }^{13} \mathrm{C}\right]$ glucose, and production of ${ }^{13} \mathrm{C}$ isotope-containing pyruvate, lactate, alanine, and the TCA cycle intermediate succinate was monitored. As expected, parental cells differed in all assessed metabolites from the two sublines. $\mathrm{SDHB}^{\mathrm{KO}} \mathrm{EV}$ cells showed increased intracellular levels of lactate and alanine compared to $\mathrm{SDHB}^{\mathrm{KO}} \mathrm{SDHA}{ }^{\mathrm{low}}$ cells,

Fig. 4 Pyrimidine biosynthesis is suppressed in the presence of $\mathrm{Cll}_{\text {low. }}$ a Label-free quantitative proteomic analysis of downregulated proteins in SDHB ${ }^{\mathrm{KO}}$ MDAMB231 cells and the percentage of proteins identified per pathway relative to genes with significantly altered expression in SDHB ${ }^{\mathrm{KO}}$ cells. $\mathbf{b}$ Scheme of the de novo pyrimidine nucleotide synthesis pathway. c SDS-PAGE following WB analysis of MDA231 sublines for proteins of the de novo pyrimidine pathway. $\mathbf{d}$ Densitometric evaluation of the level of the CAD and DHODH proteins by WB. Relative isotopomer amounts (M+1) of CTP, CDP, UTP, and UDP were assessed by LC-MS/MS using $\left[\mathrm{U}-{ }^{13} \mathrm{C}\right]$ glucose $(\mathbf{e})$ and $\left[\mathrm{U}-{ }^{13} \mathrm{C}\right]$ glutamine $(\mathbf{f})$ as tracers. Data shown are mean values \pm SD $(n \geq 3)$; images are representative of at least three independent experiments. The symbol ${ }^{\star *}$ indicates differences with $p<0.05$ and 'ns' indicates non-significant differences, as assessed by the two-tailed unpaired Student's t-test 
a
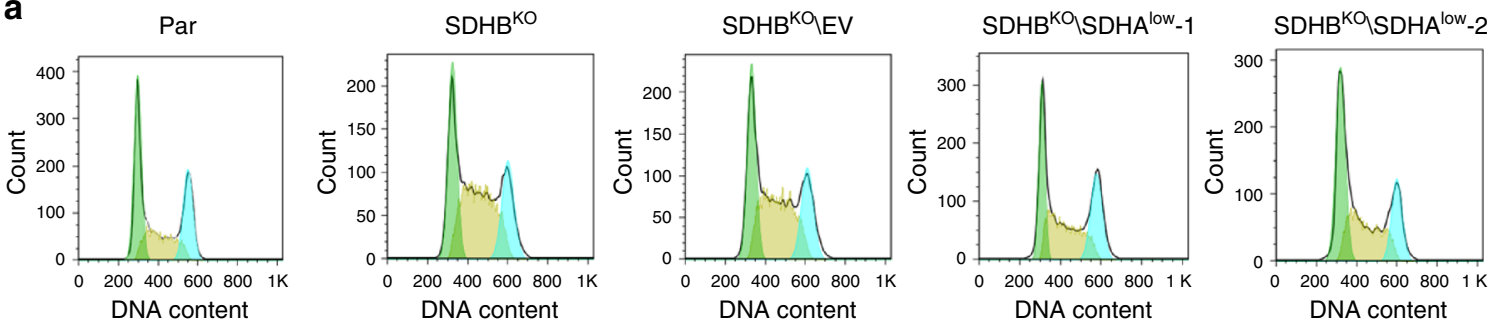

b

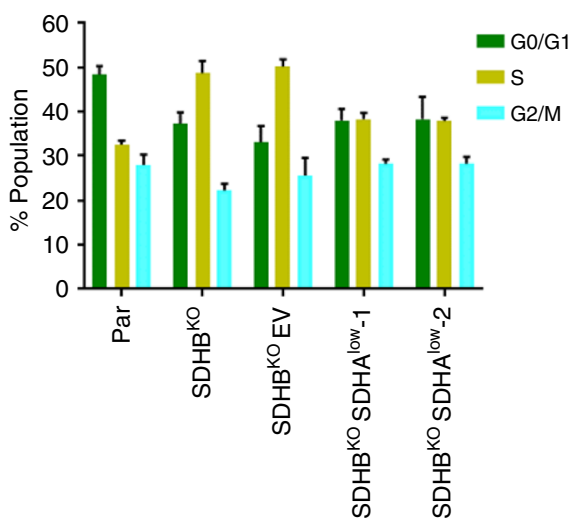

d

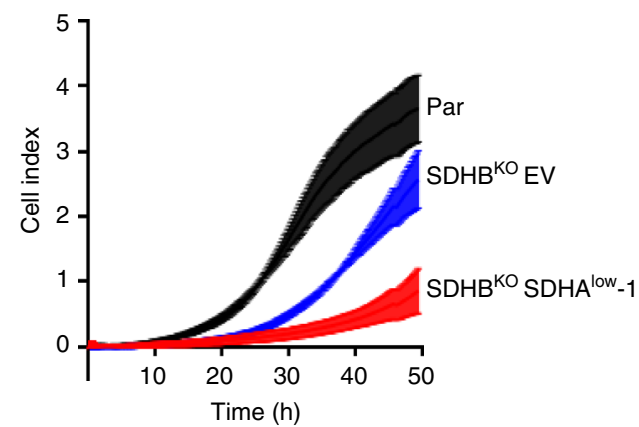

C
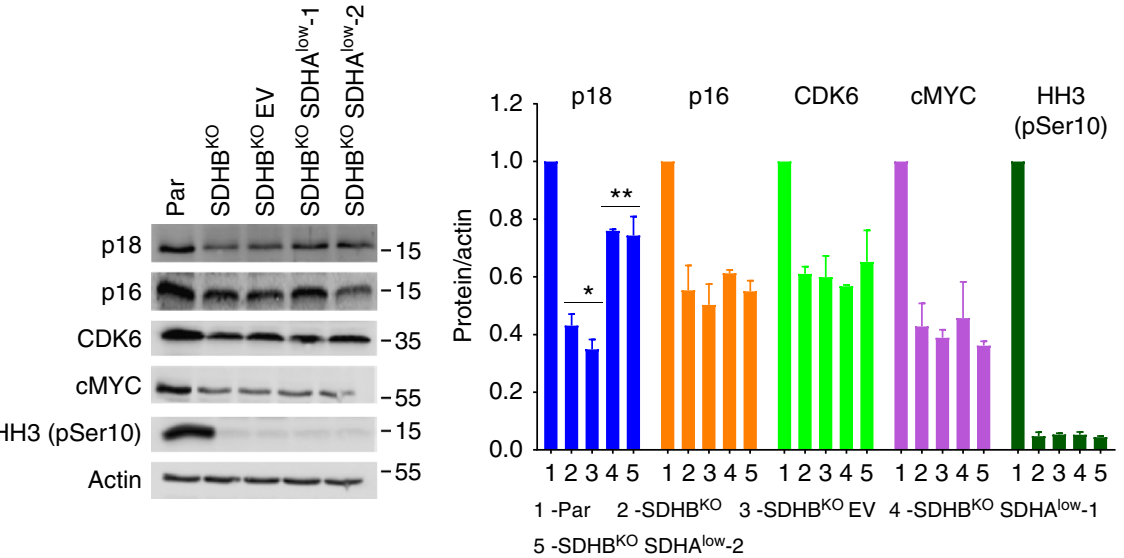

e

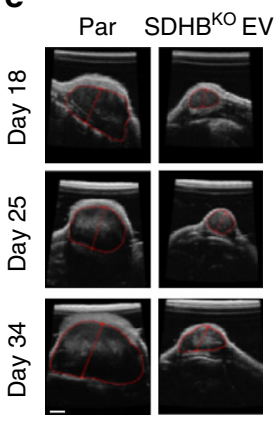

f

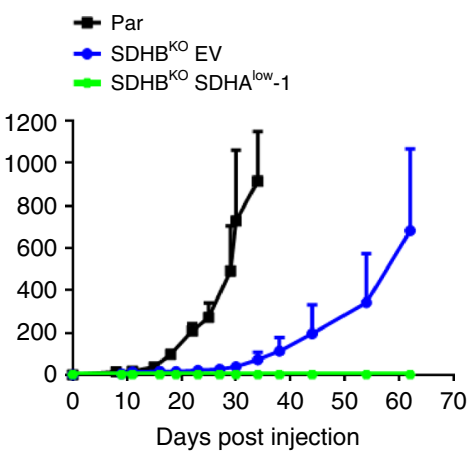

Fig. $5 \mathrm{Cll}_{\text {low }}$ supports growth of SDHB-deficient tumors. a MDA231 sublines were evaluated for cell cycle distribution using flow cytometry and staining with propidium iodide. Green color indicates cells in G0/G1 phase, yellow cells in S phase, and blue color cells in G2/M phase. b Histograms show evaluation of data in panel (a) representing $10^{4}$ cells. c SDS-PAGE followed by WB analysis of proteins linked to the regulation of cell cycle progression and mitosis; images are representative of three independent experiments. d MDA231 sublines were assessed for migration capacity using the $x$ CELLigence system. e MDA231 sublines were grafted in Balb-c nu/nu mice at $10^{6}$ cells per animal, and tumor progression was visualized and quantified by ultrasound imaging. The bar represents the size of $2 \mathrm{~mm}$. $\mathbf{f}$ Representative images of tumors derived from parental and SDHB ${ }^{\mathrm{KO}} \mathrm{EV}$ cells. Data shown are mean values $\pm \mathrm{SD}\left(n=5\right.$ for $\mathbf{b}$ and $\mathbf{c}$ ). The symbol * indicates significant differences compared to parental cells with $p<0.05$ and ${ }^{\star \star}$ significant differences compared to $\mathrm{SDHB}^{\mathrm{KO}}$ cells with $p<0.05$, as assessed by the two-tailed unpaired Student's $t$-test

while fatty acid synthesis was not altered (Fig. 6c). Therefore, reduction of $\mathrm{CII}_{\text {low }}$ in $\mathrm{SDHB}^{\mathrm{KO}} \mathrm{SDHA}{ }^{\text {low }}$ cells seems to induce shuttling of pyruvate to pathways other than glycolysis without affecting fatty acid metabolism. Importantly, $\mathrm{SDHB}^{\mathrm{KO}} \mathrm{EV}$ cells had a higher level of succinate than parental cells, in agreement with previous reports for other $\mathrm{SDHB}^{\mathrm{KO}}$ models ${ }^{40-44}$. However, $\mathrm{SDHB}^{\mathrm{KO}} \mathrm{SDHA}^{\text {low }}$ cells showed reduced succinate levels compared to $\mathrm{SDHB}^{\mathrm{KO}} \mathrm{EV}$ cells (Fig. 6c), suggesting a $\mathrm{CII}_{\text {low-depen- }}$ dent change in succinate metabolism, which may be due to activation of an alternative metabolic route of succinate utilization.

$\mathrm{CII}_{\text {low }}$ negatively regulates anabolic activity of TCA cycle. To obtain further insight into succinate metabolism as well as metabolism of other TCA cycle intermediates, we monitored the fate of $\left[\mathrm{U}_{-}{ }^{13} \mathrm{C}\right]$ glucose and $\left[\mathrm{U}_{-}{ }^{13} \mathrm{C}\right]$ glutamine in MDA231 sublines using LC-MS. The first cycle of TCA metabolism of $\left[\mathrm{U}^{13} \mathrm{C}\right]$ glucose via acetyl-CoA will generate fourcarbon metabolites with two ${ }^{13} \mathrm{C}$ nuclei $(\mathrm{m}+2$ isotopomer) through oxidative decarboxylation (Fig. 7a-f). Alternatively, an $\mathrm{m}$ +3 isotopomer can be formed if glucose enters the TCA cycle via the pyruvate carboxylase (PC) pathway (Fig. 7a). In agreement with the above NMR data (Fig. 6c), we observed increased $\mathrm{m}+2$ isotopomers of succinate in $\mathrm{SDHB}^{\mathrm{KO}} \mathrm{EV}$ cells, and this was reduced in $\mathrm{SDHB}^{\mathrm{KO}} \mathrm{SDHA}^{\text {low }}$ cells (Fig. 7d). Concurrently, the levels of $\mathrm{m}+2$ isotopomers of aspartate, malate, and fumarate increased in $\mathrm{SDHB}^{\mathrm{KO}} \mathrm{SDHA}^{\text {low }}$ cells compared to $\mathrm{SDHB}^{\mathrm{KO}} \mathrm{EV}$ cells (cf. Fig. 7e-g), suggesting more efficient consumption of succinate in cells with lower levels of $\mathrm{CII}_{\text {low }}$. The increase in $\mathrm{m}+3$ 
a
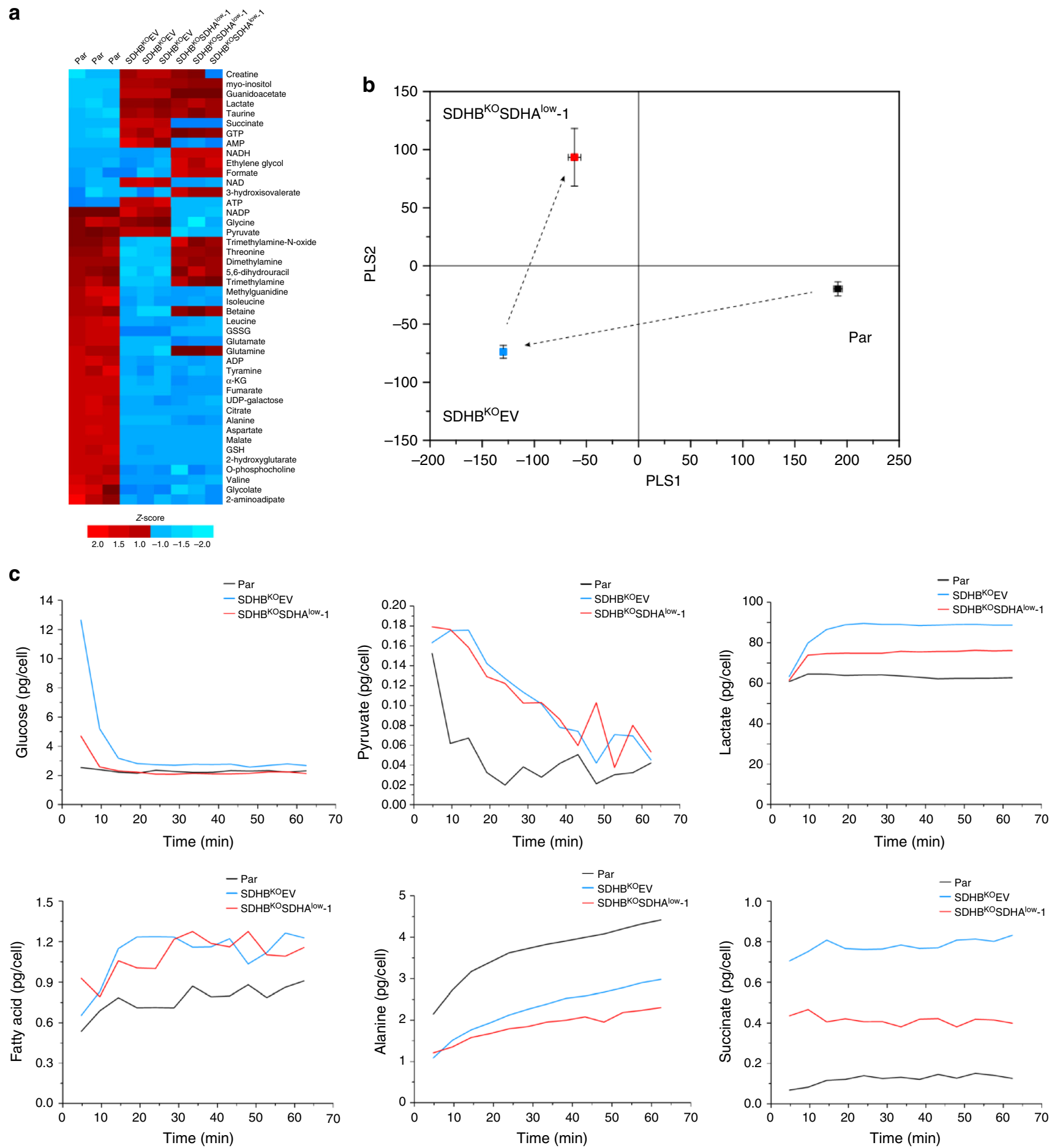

Fig. $6 \mathrm{Cll}_{\text {low }}$ modulates metabolome of MDA231 sublines. a The heat map was constructed with the Z-score of peak intensities of each metabolite identified by both $1 D$ NMR and LC-MS/MS from parental, SDHB ${ }^{K O} E V$, and SDHB ${ }^{K O} S D H A{ }^{\text {low }}$ cells. The Z-score was obtained by dividing the difference between actual peak intensities and mean value by the standard deviation. $\mathbf{b}$ Score plot from partial least squares discriminant analysis (PLS-DA) on MDA231 sublines with the entire 1D NMR spectral data. PLS1 axis accounts for the major metabolic discrimination (63.5\%), and the PLS2 16.8\%. The symbols represent the mean score values from the multivariate analysis and the whiskers represent one standard deviation. Transitions are shown by arrows. c Real-time flux comparison in live parental, $\mathrm{SDHB}{ }^{\mathrm{KO}} \mathrm{EV}$, and $\mathrm{SDHB} \mathrm{KO}_{\mathrm{SDHA}}{ }^{\text {low }}$ cells. Time-dependent metabolic changes were obtained using $2 \mathrm{D}$ in-cell NMR metabolomics approach. The absolute quantification is based on the level of ${ }^{13} \mathrm{C}$ carbon on a particular atom of metabolites detectable by NMR and was performed as described previously ${ }^{39}$. Although it is not possible to differentiate pre-existing natural abundance metabolites with those derived from ${ }^{13} \mathrm{C}$-glucose with real-time NMR, the natural abundance of ${ }^{13} \mathrm{C}$ is $1 \%$ and pre-existing metabolites should not make significant contributions to the quantitation. Fatty acid represents the aggregate level of the ${ }^{13} \mathrm{C}$-labeled $\mathrm{CH}_{2}$ peak from free fatty acids at 1.36 and $32.0 \mathrm{ppm}$ on the $\mathrm{HSQC}$ spectrum. Parental, black; $\mathrm{SDHB}^{\mathrm{KO}} \mathrm{EV}$, blue; $\mathrm{SDHB}^{\mathrm{KO}} \mathrm{SDHA}{ }^{\text {low }}$, red 
isotopomer of aspartate and malate in $\mathrm{SDHB}^{\mathrm{KO}} \mathrm{SDHA}^{\text {low }}$ cells, but not that of fumarate (Fig. 7e-g), suggests that the PC pathway may also contribute to the four-carbon metabolites in these cells.

$\left[\mathrm{U}_{-}{ }^{13} \mathrm{C}\right]$ glutamine feeds carbons into the TCA cycle via $\alpha-$ ketoglutarate. A subsequent oxidative decarboxylation in the TCA cycle generates the $\mathrm{m}+4$ isotopomer of succinate that can lead to $\mathrm{m}+4$ aspartate (Fig. $7 \mathrm{~h}, \mathrm{j}-\mathrm{n}$ ). Succinate and aspartate $\mathrm{m}+2$ isotopomers can also be formed through the TCA cycle if the $\mathrm{m}+4$ succinate condenses with acetyl-CoA, followed by oxidative decarboxylation in subsequent TCA cycles (Fig. 7h, green). [U${ }^{13} \mathrm{C}$ ] glutamine can also contribute to formation of the $\mathrm{m}+3$ isotopomer of aspartate via reductive carboxylation (Fig. 7h, red). In parental cell lines, we observed simultaneous oxidative decarboxylation and reductive carboxylation of glutamine as

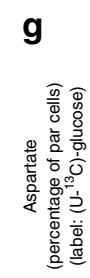

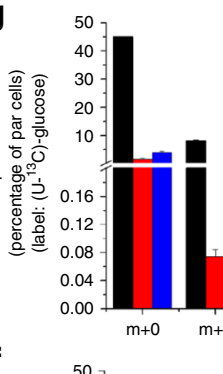

$\mathbf{f}$
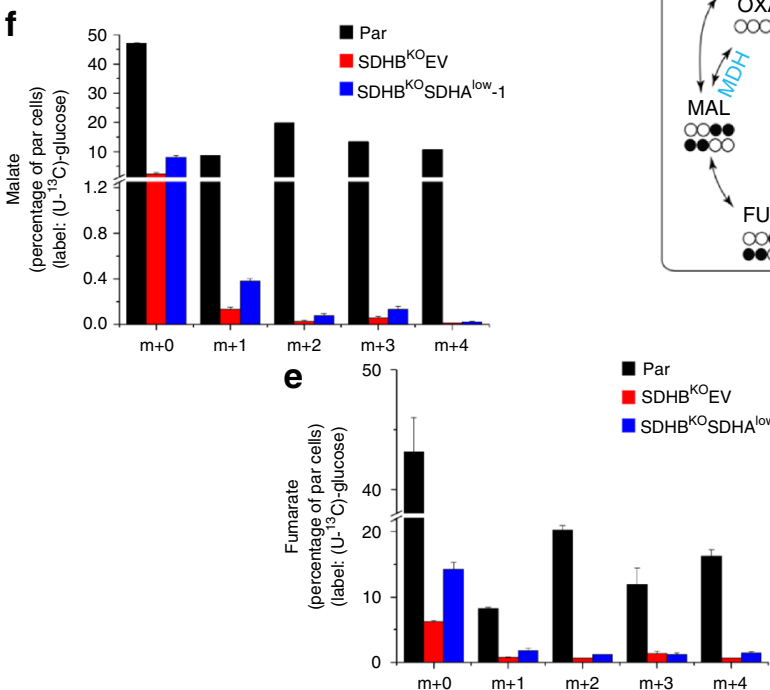

n
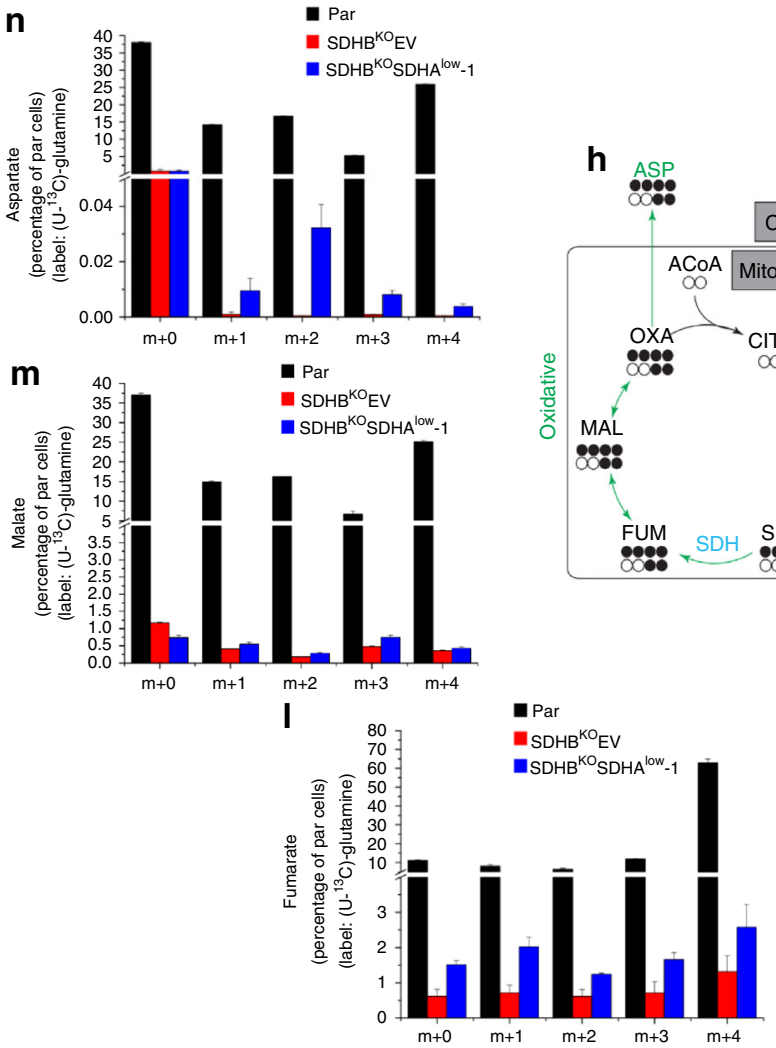
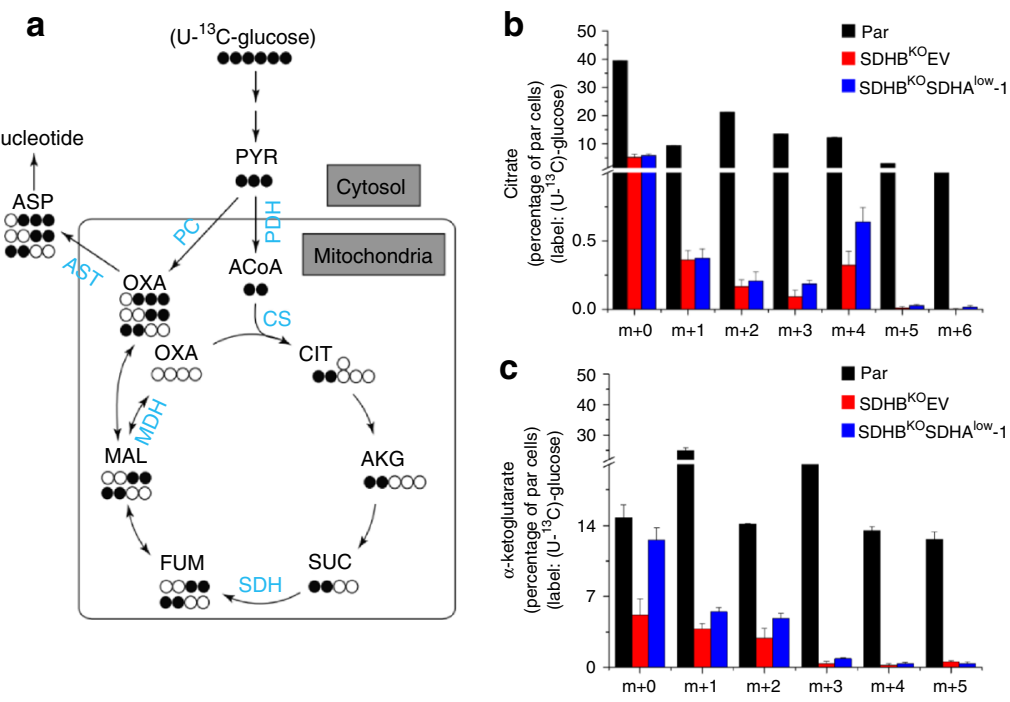

- Par

- $\mathrm{SDHB}^{\mathrm{KO}} \mathrm{EV}$

- $\mathrm{SDHB}^{\mathrm{KO}} \mathrm{SDHA}^{\mathrm{low}}-1$

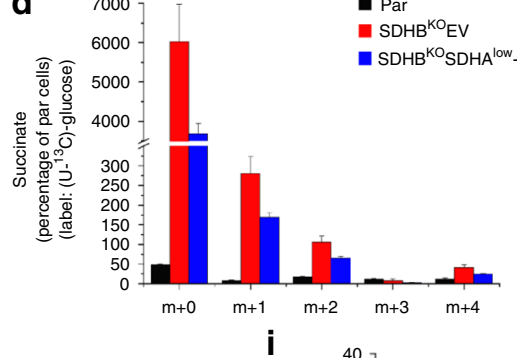

i
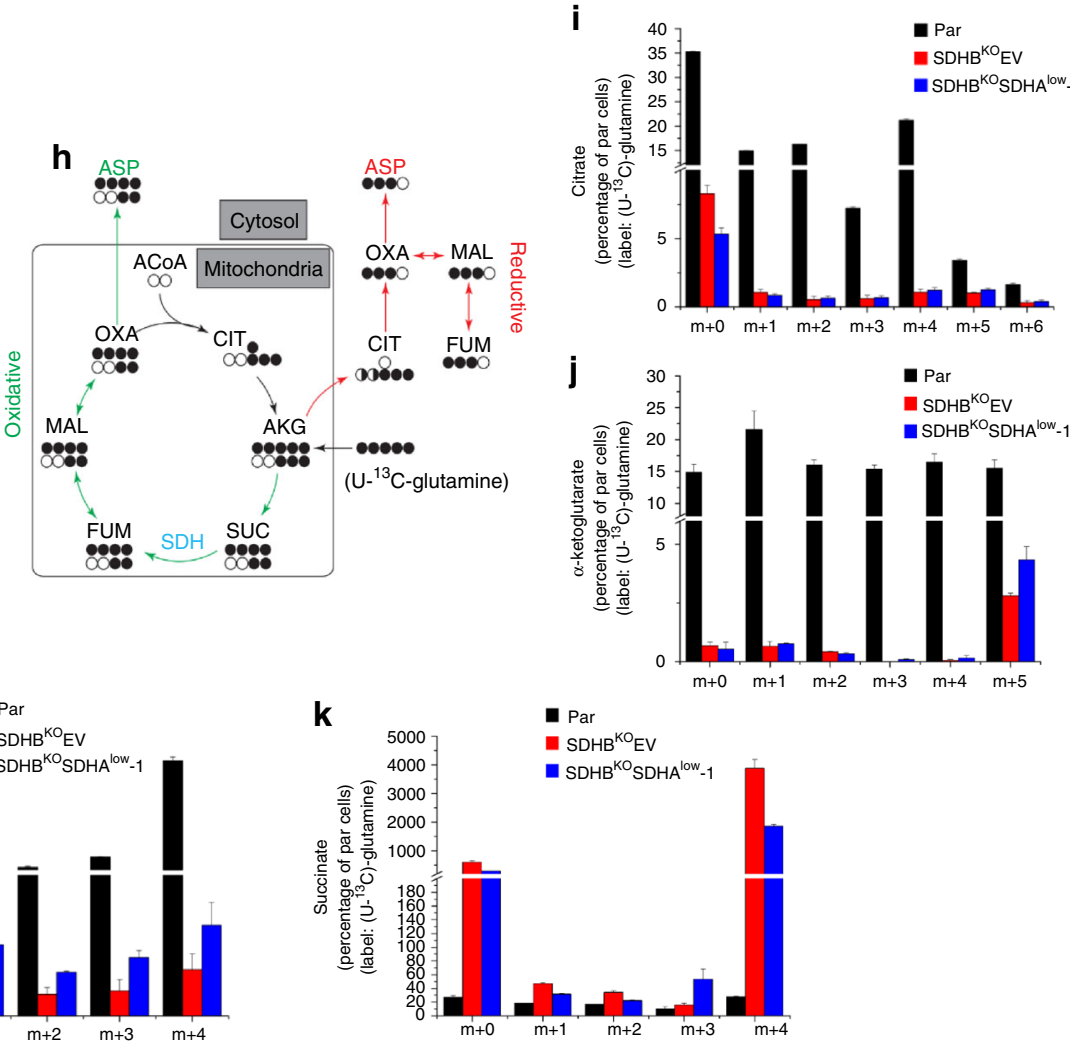
Fig. $7 \mathrm{Cll}_{\text {low }}$ restricts TCA-linked anabolism. a and $\mathbf{h}$, Predicted labeling patterns of indicated metabolites from $\mathrm{U}_{-}{ }^{13} \mathrm{C}_{6}$-glucose $(\mathbf{a})$ and from U- ${ }^{13} \mathrm{C}$-glutamine (h) (filled circles ${ }^{13} \mathrm{C}$; open circles ${ }^{12} \mathrm{C}$ ). The oxidative (green) and reductive (red) carboxylation pathways are indicated $(\mathbf{h})$. Isotopologue distribution of intracellular citrate $(\mathbf{b}, \mathbf{i})$, a-ketoglutarate $(\mathbf{c}, \mathbf{j})$, succinate $(\mathbf{d}, \mathbf{k})$, fumarate $(\mathbf{e}, \mathbf{I})$, malate $(\mathbf{f}, \mathbf{m})$, and aspartate $(\mathbf{g}, \mathbf{n})$ after incubation for $24 \mathrm{~h}$ with $5 \mathrm{mM}$ unlabeled glucose and $20 \mathrm{mM} \mathrm{U-}{ }^{13} \mathrm{C}$-glucose or $4 \mathrm{mM} \mathrm{U-}{ }^{13} \mathrm{C}$-glutamine, respectively. The data were obtained using LC-MS/MS analysis. The $Y$ values are presented as the percent values of the sum of all the isotopologues per each metabolite in parental cells; ' $m+$...' indicates the relevant isotopomer. Data are presented as mean \pm SD, $n=3$. PYR pyruvate, ACoA acetyl-CoA, CIT citrate, AKG $\alpha$-ketoglutarate, SUC succinate, FUM fumarate, MAL malate, OXA oxaloacetate, ASP aspartate, PDH pyruvate dehydrogenase, PCX pyruvate carboxylase, CS citrate synthase, SDH succinate dehydrogenase, MDH malate dehydrogenase, AST aspartate transaminase

shown by high levels of incorporation of [U- $\left.{ }^{13} \mathrm{C}\right]$ glutamine into $\mathrm{m}+2, \mathrm{~m}+3$, and $\mathrm{m}+4$ aspartate isotopomers (Fig. $7 \mathrm{n}$ ), consistent with reports on other cancer cells ${ }^{45-48}$. Significant formation of $\mathrm{m}$ +5 citrate isotopomer also suggests reductive carboxylation in parental cells (Fig. 7i). We observed very high absolute incorporation of $\left[\mathrm{U}^{13} \mathrm{C}\right]$ glutamine into $\mathrm{m}+4$ succinate in $\mathrm{SDHB}^{\mathrm{KO}} \mathrm{EV}$ and a significant decrease to about half in $\mathrm{SDHB}^{\mathrm{KO}} \mathrm{SDHA}^{\text {low }}$ cells (Fig. $7 \mathrm{k}$ ). These were accompanied by higher incorporation of $\left[\mathrm{U}_{-}{ }^{13} \mathrm{C}\right]$ glutamine into $\mathrm{m}+4$ aspartate and fumarate in $\mathrm{SDHB}^{\mathrm{KO}} \mathrm{SDHA}{ }^{\text {low }}$ cells than $\mathrm{SDHB}^{\mathrm{KO}} \mathrm{EV}$ cells (Fig. $7 \mathrm{l}$ and $\mathrm{n}$ ). Similar patterns were observed for the $\mathrm{m}$ +2 succinate isotopomer (Fig. 7k), although the absolute incorporation was much lower, probably due to a second round of the TCA cycle. These glutamine incorporation data clearly indicate that glutamine-derived succinate accumulates in $\mathrm{SDHB}^{\mathrm{KO}} \mathrm{EV}$ cells, whereas it is converted to fumarate and ultimately to aspartate more efficiently in $\mathrm{SDHB}^{\mathrm{KO}} \mathrm{SDHA}^{\text {low }}$ cells.

Overall, both glucose and glutamine isotope incorporation experiments indicate a block in succinate metabolism in $\mathrm{SDHB}^{\mathrm{KO}} \mathrm{EV}$ cells that is at least partially lifted when the $\mathrm{CII}_{\text {low }}$ is depleted on the $\mathrm{SDHB}^{\mathrm{KO}}$ background (Supplementary Fig. 5a and $\mathrm{c}$ ). This phenomenon is also consistent with the reverse trend of fumarate, whose level increased in $\mathrm{SDHB}^{\mathrm{KO}} \mathrm{SDHA}^{\text {low }}$ cells (Supplementary Fig. 5b and d). This re-flow of succinate is suggested to induce redistribution of carbon atoms of glucose and glutamine to four-carbon metabolites leading to the recovery of synthesis of aspartate, a precursor for pyrimidine synthesis.

Previous studies showed that CII dysfunction caused by SDHB-SDHD mutations/deficiency results in accumulation of succinate $e^{2,40,42-44,49,50}$. Here we demonstrate that SDHA maintains high levels of succinate following CII dysfunction. Our data also implicate a switch of carbon metabolism in a $\mathrm{CII}_{\mathrm{low}^{-}}$ dependent manner, mainly from succinate accumulation to anabolic reactions, including synthesis of aspartate to produce pyrimidines. Further investigations are needed to elucidate the enzymatic activity of $\mathrm{CII}_{\text {low }}$, especially in the context of succinate accumulation due to reductive carboxylation of glutamine (Fig. 7h).

$\mathrm{CII}_{\text {low }}$ is a feature of SDHB-deficient paraganglioma. To assess the clinical relevance of our findings, we inspected tumor tissue from paraganglioma patients with SDHA and $S D H B$ mutations, as well as sporadic paraganglioma patients. We assessed tumors from six patients for the presence of SDHA and SDHB using immunohistochemistry. Fig. 8a shows that samples from patients with mutated $S D H B$ exhibit high levels of SDHA, while tumor tissue derived from a patient with SDHA mutation showed very low levels of both SDHA and SDHB proteins. Next, tumors of these patients were evaluated for CII assembly and for the level of de novo pyrimidine synthesis. The rate-limiting trifunctional CAD protein as well as cell cycle regulatory proteins were assessed. NBGE showed high levels of $\mathrm{CII}_{\text {low }}$ and low levels of fully assembled CII in tumors with $S D H B$ mutations, while tumors with SDHA mutations showed low levels of fully assembled CII and the absence of $\mathrm{CII}_{\text {low }}$ (Fig. 8b). Further, SDHA- mutated paragangliomas lacked FAD, a cofactor of CII associated with the catalytic subunit SDHA, while it was detected in sporadic paragangliomas or those with $S D H B$ mutations. Paragangliomas with high levels of $\mathrm{Cll}_{\text {low }}$ were found to contain low levels of CAD and p18 (Fig. 8c and d). These data are in agreement with results found for sublines of MDA231 cells with different CII assembly status (Fig. 2d; Fig. 4c; Fig. 5c). The data imply that $\mathrm{CII}_{\text {low }}$ may vary under different (patho)physiological conditions, giving our findings clinical relevance.

\section{Discussion}

In the present study, we show that alternative assembly of CII fine-tunes cellular metabolic homeostasis to compensate for chronic bioenergetic stress. SDHA is known to exist in a complex with other subunits of CII, with an overall molar mass of 124 $\mathrm{kDa}$, migrating on native gels at $\sim 140 \mathrm{kDa}^{22,51}$. We found an assembly form of SDHA migrating at $\sim 100 \mathrm{kDa}$ (designated here as $\mathrm{CII}_{\text {low }}$; Figs. 1 and 2), lacking SDHB and SDHC. This is consistent with previous studies using an experimental model of yeast, mammalian cell culture, and human pathological conditions showing that SDHA is stable in the absence of $\mathrm{SDHB}^{40-}$ 44,52 , although its biological function has never been investigated. In addition, $\mathrm{CII}_{\text {low }}$ is more prevalent when mtDNA is depleted or its expression is compromised (Fig. 1). This suggests biological relevance of $\mathrm{CII}_{\text {low }}$ with mtDNA mutations and under conditions that limit mitochondrial energy production. We propose that CII/ $\mathrm{CII}_{\text {low }}$ has a role in mitochondria similar to that of pyruvate kinase 2 (PKM2), which changes its assembly from a highly active tetrameric to low-active dimeric form in response to different cellular signaling pathways. A switch from the tetrameric to dimeric form of PKM2 has profound consequences for cellular metabolism as well as proliferation in the context of diabetic nephropathy ${ }^{53}$ and tumorigenic capacity of cancer cells ${ }^{54-56}$.

The molecular weight of SDHA is about $70 \mathrm{kDa}$ and thus there are likely to be other SDHA-interacting proteins in $\mathrm{CII}_{\text {low }}$ of approximately $100 \mathrm{kDa}$. To identify SDHA-interacting proteins, we used immunoprecipitation followed by MS analysis. This analysis, supported by WB, identified the assembly factors SDHAF2 and SDHAF4 as proteins that together with SDHA constitute $\mathrm{CII}_{\text {low }}$ accounting for its $\sim 100 \mathrm{kDa}$ mass (Supplementary Fig. 2). We have recently reported that SDHAF2 has redundant function in relation to CII activity in MDA231 cells ${ }^{57}$. While we do not know the function of SDHAF2 and SDHAF4 in $\mathrm{CII}_{\text {low }}$, it is possible that these factors form a functional association with SDHA within $\mathrm{CII}_{\text {low }}$ and in the absence of the other three subunits (SDHB-D). The role of SDHAF2 and SDHAF4 in $\mathrm{CII}_{\text {low }}$ is the subject of current investigation.

To study the cellular function of $\mathrm{CII}_{\text {low }}$, we established stable cellular models with three different assembly forms of SDHA (Fig. 2) and initially analyzed bioenergetics difference of these sublines. We found that $\mathrm{SDHB}^{\mathrm{KO}}$ cells with prominent presence of $\mathrm{CII}_{\text {low }}$ switched to low basal respiration with no spare respiratory capacity, indicating an energy stress situation. $\mathrm{SDHB}^{\mathrm{KO}} \mathrm{SDHA}{ }^{\text {low }}$ cells with depleted $\mathrm{CII}_{\text {low }}$ showed a bioenergetic pattern similar to that of $\mathrm{SDHB}^{\mathrm{KO}}$ cells (Fig. 3), indicating 
a

\section{के}

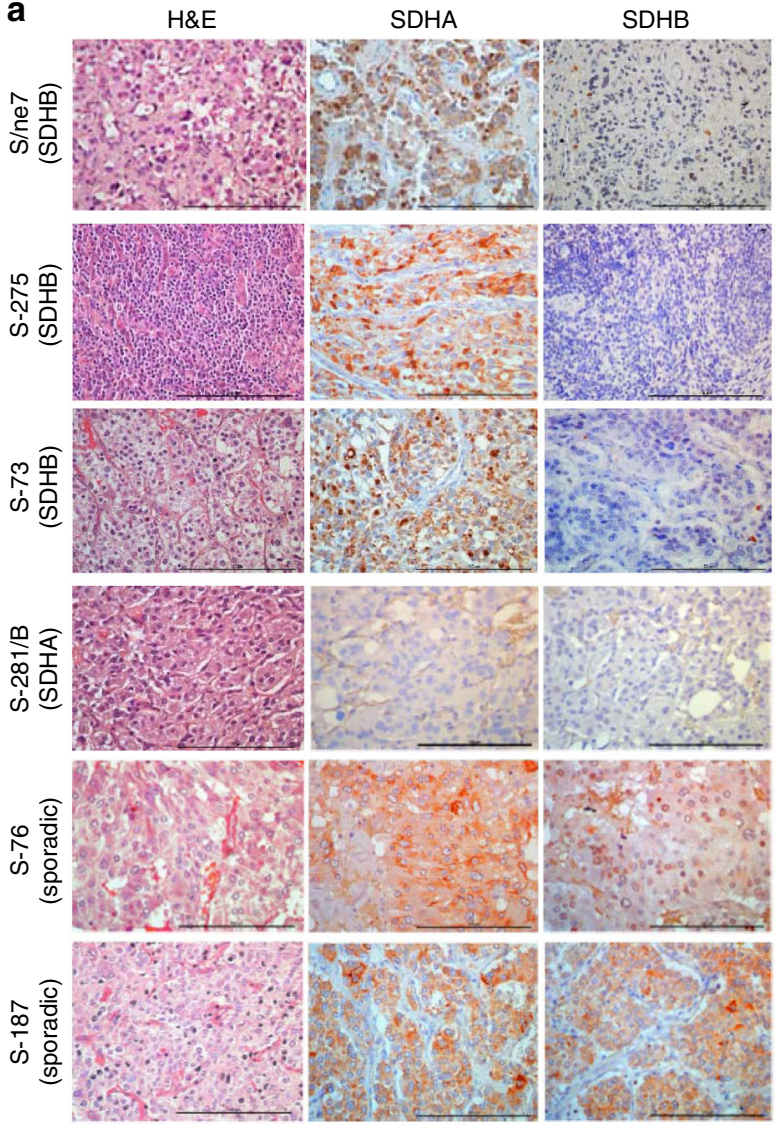

$$
\text { ஸे }
$$

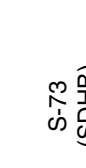

b

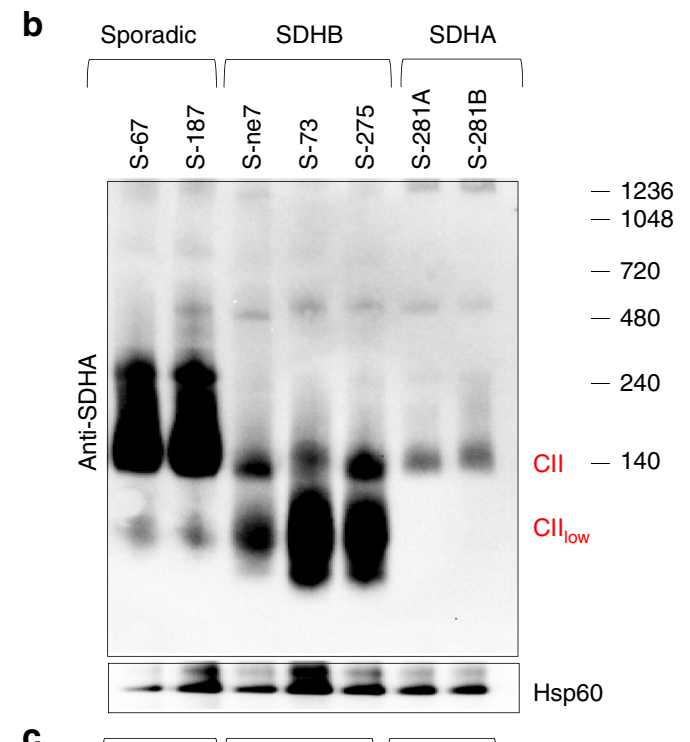

C
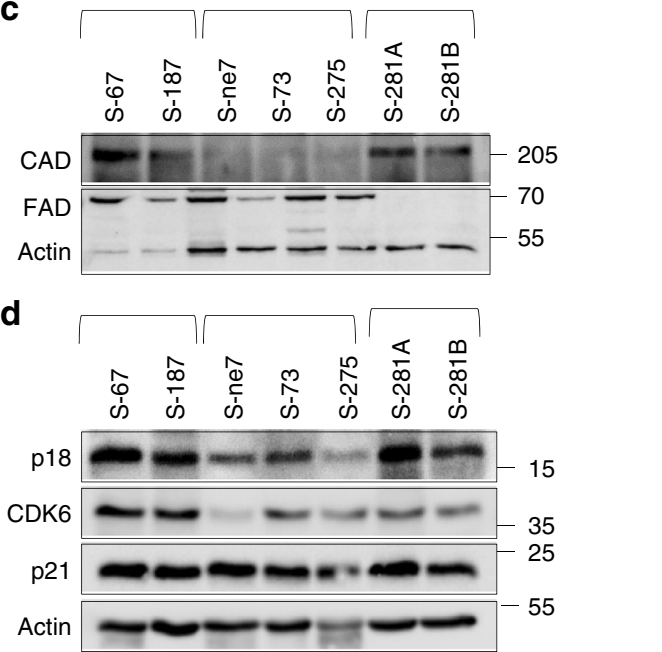

Fig. $8 \mathrm{Cll}$ assembly and de novo pyrimidine pathway in paragangliomas. a Histological examination of SDHA and SDHB expression from tumor tissue of paraganglioma patients with SDHA or SDHB mutations or with sporadic paragangliomas. Tissues were processed for H\&E staining and immunohistochemistry using SDHA and SDHB IgGs. Representative images are collected using a 40× objective. Scale bars represent $100 \mu \mathrm{m}$. b-d Paraganglioma tissues, as shown, were assessed by WB following protein separation by NBGE for CII assembly using anti-SDHA IgG (b), and by SDS-PAGE for CAD and FAD (c) and for markers of cell cycle (d). Images are representative of three independent experiments

that $\mathrm{CII}_{\text {low }}$ plays only a minimal role in mitochondrial bioenergetics.

Label-free proteomic and pathway analysis allowed for identification of differences in the de novo pyrimidine pathway in MDA231 sublines. We found that $\mathrm{CII}_{\text {low }}$ abundance is inversely correlated with de novo pyrimidine pathway activity (Fig. 4), as exemplified by the steady-state level of CAD, a trifunctional and rate-limiting polypeptide in the pathway. The level of the CAD protein was reduced by approximately $60 \%$ in $\mathrm{SDHB}^{\mathrm{KO}}$ cells resulting in cell cycle arrest in the S-phase, and its re-expression in $\mathrm{SDHB}^{\mathrm{KO}} \mathrm{SDHA}{ }^{\text {low }}$ cells with depleted $\mathrm{CII}_{\text {low }}$ normalized cell cycle progression (Fig. 5). Recently, the de novo pyrimidine synthesis pathway has been shown to be essential in metabolic rewiring that modulates chemotherapy resistance of triplenegative breast cancer ${ }^{58}$ and other neoplastic pathologies 59,60 , supporting the notion that de novo pyrimidine synthesis improves plasticity of cancer cells at the expense of increased energy consumption. Further investigations will be needed to provide unequivocal evidence for a functional linkage between $\mathrm{CII}_{\text {low }}$ and pyrimidine biosynthesis. However, our data suggest that $\mathrm{CII}_{\text {low }}$ exerts its protective function not by modulating mitochondrial bioenergetics (i.e., OXPHOS), but through other mitochondria-related mechanisms, which are not yet fully defined but seem to involve energy conservation strategies such as a reduction of the de novo pyrimidine synthesis pathway. Therefore, we propose that restriction of this pathway and possibly of other energy-demanding processes by $\mathrm{Cll}_{\text {low }}$ may provide a selective advantage under suboptimal nutrient conditions when bioenergetics is compromised, exemplified by increased cell death in galactose media and a the failure to form tumors in a mouse xenograft model (Fig. 5) when SDHB-deficient cells lose $\mathrm{CII}_{\text {low. }}$. In line with this, $\mathrm{CII}_{\text {low }}$ is less abundant in optimal physiological conditions and becomes the dominant SDHA form of CII during sub-optimal energy production (Fig. 1).

Our data suggest that deficiency of CII assembly and the shift of SDHA to $\mathrm{CII}_{\text {low }}$ modulates metabolism in response to compromised mitochondrial bioenergetics. It introduces checkpoints of cellular functions with high demands for energy, for example reducing formation of aspartate that is essential for pyrimidine nucleotide synthesis. This indicates that $\mathrm{CII}_{\text {low }}$ might be a sensor of bioenergetic stress, providing a feedback from OXPHOS to central carbon metabolism. Similarly, a number of proteins 
capable of sensing mitochondrial energy production or metabolite levels that reflect energy status have been identified. AMPactivated protein kinase (AMPK) has been shown to sense the ratio of ATP to ADP and AMP level in order to initiate an energy compensating stress response ${ }^{61,62}$. Previous studies have also demonstrated that certain sirtuins are sensors of organelle energy production in relation to the NADH/NAD ${ }^{+}$ratio $^{63}$. Recently the ubiqunol/ubiqunone ratio has been reported to sense mitochondrial energy production linked to the respiratory status ${ }^{64}$. Possible links between CII assembly forms and other sensors of mitochondrial bioenergetic dysfunction need to be further investigated. Merging these various individual components into a highly integrated regulatory system presents the next challenge.

Data shown here reveal that patients with $S D H B$ and SDHA mutations have different CII assembly status. We found that $\mathrm{CII}_{\text {low }}$ is the remaining unit of CII present in patients with $S D H B$ mutations, but is absent in patients with SDHA and sporadic mutations. In agreement with our cellular model of MDA231 sublines, patients that show high levels of $\mathrm{CII}_{\text {low }}$ also have reduced levels of the de novo pyrimidine synthesis regulatory enzyme CAD and the cell cycle modulator protein p18 (Fig. 8). Clinical data also indicate that SDHB mutationassociated paragangliomas are less proliferative but are associated with higher invasiveness and metastasis ${ }^{42,65-67}$. This may be one of the reasons why SDHA-deficient tumors are relatively rare, possibly due to an imbalance in energy and metabolic homeostasis. Thus, our data provide more detailed insights into established clinic-pathological features for incurable $S D H x$-related paragangliomas and may potentially serve as a diagnostic marker.

In summary, we found that following mtDNA depletion or SDHB deficiency, an alternative CII with different activity is formed. We suggest that the existence of $\mathrm{CII}_{\text {low }}$ in patients with $S D H B$-mutated paragangliomas may contribute to a cellular mechanism resulting in severe pathological outcomes, including enhanced migration and invasiveness. Hence, SDHA epitomizes a moonlighting protein, being an enzyme that is a baseline tumor suppressor but becomes a promoter of tumor growth in the context of bioenergetic deficiency.

\begin{abstract}
Methods
Cells and transfection. MDA231 and MCF7 cells were obtained from the ATCC and cultured in DMEM (Life Technology) supplemented with 10\% FCS and antibiotics plus antimycotics (Gibco). To generate $\mathrm{SDHB}^{\mathrm{KO}}$ cell lines,

MDA231 cells were transfected with the TALEN construct obtained from Genecopoeia. Transfections were performed using Lipofectamine 2000 (Invitrogen) according to the manufacturer's instructions; transfectants were selected with hygromycin. Two shRNAs targeting the human SDHA gene and empty vector (EV) were purchased from OriGene. SDHB ${ }^{\mathrm{KO}}$ cells were transfected with the shRNA plasmids. After $36 \mathrm{~h}$, cells were treated for 5 days with $0.8 \mu \mathrm{g} / \mathrm{ml}$ puromycin. Preparation of mtDNA-depleted cells $\left(4 \mathrm{~T} 1 \rho^{0}\right.$ and MCF7 $\left.\rho^{0}\right)$ was accomplished by their long-term incubation with $50 \mu \mathrm{M} \mathrm{EtBr}{ }^{13,57}$. Human SDHB was re-expressed in SDHB ${ }^{\mathrm{KO}}$ cells from the pLYS5-SDHB-Flag plasmid ${ }^{68}$ (Addgene \# 50055, a kind gift of Vamsi Mootha) using lentiviral transduction. Lentivirus particles were produced in Hek293T cells using second generation psPAX and pMD.2G plasmids and lipofection (Lipofectamine 3000, Invitrogen). Virus-containing media were collected after $48 \mathrm{~h}$, centrifuged at $3000 \times \mathrm{g}$ for $15 \mathrm{~min}$ and stored at $-80^{\circ} \mathrm{C}^{69}$.
\end{abstract}

\footnotetext{
Proliferation, migration, and cell death assays. Parental, $\mathrm{SDHB}^{\mathrm{KO}} \mathrm{EV}$, and $\mathrm{SDHB}^{\mathrm{KO}} \mathrm{SDH} \mathrm{A}^{\text {low }}$ cells were plated in a 24 -well dish in DMEM. At indicated times, cell proliferation was assessed by crystal violet assay using a standard protocol. xCELLigence Real-Time Cellular Analysis system was used to evaluate cell proliferation in glucose- or galactose-containing medium and using dialyzed FBS (Gibco). For this, cells were seeded in 16-well E-plates (4 replications per cell type) as recommended by the manufacturer. For migration assays, cells were transferred to the CIM-16 plates and allowed to migrate toward FBS placed in the other compartment. Cell proliferation was monitored in real time using the xCELLigence instrument for $50 \mathrm{~h}$, and the cell index was recorded every $5 \mathrm{~min}$. Cell death was assessed using the standard annexin V/propidium iodide (PI) method.
}

siRNA transfections. Mouse Silencer-select pre-designed SDHA-, SDHB-, and SDHC-targeting siRNAs and non-silencing controls were obtained from Life Technologies. The sequences are as follows: SDHA target sequence-1 (s84146): GGA ACA CUC CAA AAA CAG Att; SDHA target sequence-2 (s211850): CCA GUU AUU UUG UGG AAU Att; SDHB target sequence-1 (s205969): GCU UUA AUC AAG AUC AAG Att; SDHB target sequence-2 (s205970): CCC UCU UCC ACA UAU GUA Utt; SDHC target sequence-1 (s82476): GAU CUA CUC GGC UAA GUU Utt; SDHC target sequence-2 (s205071): GAA CAC GAG UUC AAA CCG Utt. 4T1 cells were transiently transfected with $20 \mathrm{nM}$ siRNA using Lipofectamine RNAiMAX transfection reagent (Invitrogen) according to the manufacturer's instructions and harvested for analysis $72 \mathrm{~h}$ after transfection.

Cell cycle analysis. Cells were harvested with trypsin, rinsed with PBS, fixed by drop-wise addition into $70 \%(\mathrm{v} / \mathrm{v})$ ethanol and kept at $-20^{\circ} \mathrm{C}$ for at least $4 \mathrm{~h}$. They were then centrifuged, rinsed in PBS, re-suspended in PBS containing $80 \mu \mathrm{g} / \mathrm{ml}$ RNase and $30 \mu \mathrm{g} / \mathrm{ml}$ of propidium iodide plus $100 \mu \mathrm{g} / \mathrm{ml}$ RNase A. After incubating for $30 \mathrm{~min}$ at room temperature, DNA content was assessed using the FACS Calibur flow cytometer (Becton Dickinson). Cell cycle distribution was estimated using the FlowJo software and the Watson distribution model.

Western blotting. Cells were lysed in $20 \mathrm{mM}$ Tris (pH 8), $200 \mathrm{mM} \mathrm{NaCl}, 1 \mathrm{mM}$ EDTA, $0.5 \%(\mathrm{v} / \mathrm{v}) \mathrm{NP}-40$, and $10 \%$ glycerol supplemented with protease inhibitors (Roche). After addition of the Laemmli solution to the samples, the proteins were separated by SDS-PAGE ( $8-15 \%$ gel) and then transferred to polyvinylidene difluoride (PVDF) membranes. After blocking with $5 \%$ non-fat milk, the blots were incubated with the primary antibodies overnight at $4{ }^{\circ} \mathrm{C}$. The membranes were then treated with horseradish peroxidase-conjugated secondary antibodies for $2 \mathrm{~h}$ at room temperature, followed by visualization (SuperSignal West Pico Chemiluminescent Substrate, Pierce). The following antibodies were used in the study: SDHA (Abcam, ab14715; 1:2000); SDHB (Abcam, ab14714; 1:1000); SDHC (Abcam, ab155999; 1:1000); HSP60 (Abcam, ab137706; 1:2000; or Cell Signaling, 12165; 1:2000); CoxVa (Abcam, ab110262, 1:2000); NDUFA9 (Life Technologies/Thermo Fisher, 459100; 1:2000); Core I/UQCRC1 (Life Technologies/Thermo Fisher, 459140; 1:2000); NDUFV1 (Abcam, ab55535; 1:1000); NDUFS8 (Abcam, ab170936; 1:1000); SDHAF2 (Cell Signaling, 45849; 1:1000); SDHAF4 (Thermo Fisher, PA5-73014; 1:1000; or Sigma, HPA031824; 1:500); FAD (MyBioSource, MBS2015613; 1:500); HRP-conjugated tubulin (Thermo Scientific, MA5-16308-HRP; 1:2000); HRPconjugated actin (Abcam, ab49900; 1:5000); actin (Abcam, ab14715 or 3700, or Cell Signaling, 4970 or 3700; all 1:3000); DHODH (Proteinech, 14877-1-AP; 1:500); CAD (Cell Signaling, 93925; 1:1000); phospho-Histone H3 (Ser10) (Cell Signaling, 3642; 1:1000); GAPDH (Cell Signaling, 8337; 1:3000). Uncropped western blots are in Supplementary Fig. 8.

Isolation of mitochondria and NBGE. Mitochondria were isolated using Dounce or Balch homogenizers, followed by standard differential centrifugation ${ }^{13,50,70}$. Experimental procedure and antibodies for NBGE were used as described previously ${ }^{57,71}$. In brief, digitonin-solubilised mitochondria were separated on NativePAGE Novex Bis-Tris 3-12\% gradient gels. After electrophoresis, the gels were incubated in transfer buffer containing $0.1 \%$ SDS for $10 \mathrm{~min}$ and proteins were transferred to PVDF membranes probed with specific antibodies (all diluted 1:500, except for VDAC1 and HSP60 diluted 1:1000) against complex I (NDUFA9, ab14713, Abcam; or NDUFB8, ab110242, Abcam), CII (SDHA, 14715, Abcam), CIII (Core2, ab14745, Abcam), CIV (COXVa, ab110262, Abcam) and CV (ATP5A, ab14748, Abcam; or ATP5B, HPA001520, Sigma Aldrich), and VDAC1 (ab15895, Abcam) or HSP60 (12165S, Cell Signaling) as the loading control.

Evaluation of oxygen consumption rate. Cells were seeded into an XFp assay microplate (Agilent) 1 day prior to evaluation. On the day of the assay, the growth medium was replaced with the XF assay medium (Agilent) supplemented with glucose and glutamine. Oxygen consumption rate (OCR) measurements were made using the Seahorse Analyzer (Agilent) with sequential addition of oligomycin, FCCP, rotenone and antimycin A (using the Mitostress kit from Agilent) according to the manufacturer's protocol. OCR measurements were adjusted based on the cell number counted at the end of the experiment.

Respiration assays. Respiration was evaluated in digitonin-permeabilized MDA231 sublines and assessed as described previously. ${ }^{72,73}$ In brief, the cells were trypsinized, washed with PBS, re-suspended at $1 \times 10^{6}$ cells per $\mathrm{ml}$ of the Mir05 medium (0.5 mM EGTA, $3 \mathrm{mM} \mathrm{MgCl}$, $60 \mathrm{mM}$ K-lactobionate, $20 \mathrm{mM}$ taurine, 10 $\mathrm{mM} \mathrm{KH}{ }_{2} \mathrm{PO}_{4}, 110 \mathrm{mM}$ sucrose, $1 \mathrm{~g} / \mathrm{l}$ essentially fatty acid-free bovine serum albumin, $20 \mathrm{mM}$ Hepes, pH 7.1 at $30^{\circ} \mathrm{C}$ ) and transferred to the chamber of the Oxygraph-2k instrument (Oroboros). Respiration measurements were performed at $37^{\circ} \mathrm{C}$. Cells were permeabilized with $5 \mu \mathrm{g}$ digitonin per $10^{6}$ cells, followed by sequential additions of substrate and inhibitors. CI respiration was assessed in the presence of glutamate/ malate and ADP, while CII respiration in the presence of succinate, ADP, and rotenone. 
Xenograft experiments. All procedures with animals were performed according to the Institutional guidelines and ethical authorization by the Griffith University Animal Ethics Committee. MDA231 sublines were injected into the mammary fat pad of Balb-c nu/nu mice at $10^{6}$ cells per animal. Tumor volume was quantified using the Vevo3100 USI system using a $30-\mu \mathrm{m}$ resolution scan-head ${ }^{70,74}$.

SWATH proteomic analysis. For proteomic analysis, cell pellets were lysed using $200 \mu \mathrm{l}$ of sodium deoxycholate buffer $(0.1 \%$ in $0.1 \mathrm{M}$ triethyl ammonium bicarbonate). Following reduction with $5 \mathrm{mM}$ dithiothretol and alkylation with $10 \mathrm{mM}$ iodoacetamide, $100 \mu \mathrm{g}$ of protein was digested with sequencing grade trypsin (Promega) at $37^{\circ} \mathrm{C}$ for $16 \mathrm{~h}$. The sample was acidified using formic acid and centrifuged for $10 \mathrm{~min}$ to remove the precipitated sodium deoxycholate salt. Tryptic peptides were recovered and fractionated using High $\mathrm{pH}$ Reversed-Phase Peptide Fractionation Kit (Pierce) according to manufacturer's instructions, with the exception that only six fractions were collected. To establish a reference spectral library for SWATH analysis, the fractionated sample was run by nanoLC-MS/MS using a $100 \mathrm{~mm} \times 150 \mu \mathrm{m} \mathrm{C18}$ column coupled to an Eksigent Ultra system over 90 min as described ${ }^{75}$ using Information-Dependent Acquisition (IDA) on a 5600 + Triple TOF mass spectrometer (Sciex, Framingham, MA) using the Top 10 most intense multiply charged ions. MS/MS was conducted for 50 ms over the 100-1500 $\mathrm{m} / \mathrm{z}$ range. Peptides were identified using ProteinPilot (v4.2) (Sciex) to search the UniProt Human protein database (20,198 entries, downloaded June 2015) and false-discovery controlled by searching a reversed-decoy Human database of identical size, selecting $>99 \%$ confidence for protein identification. The Paragon group file was imported into PeakView software 2.1 using the SWATH MicroApp 2.0 to generate a sample specific spectral library.

For SWATH data acquisition of individual samples, we used the same MS setup but adjusted the method to use 60 variable $\mathrm{m} / z$ windows $(400-1250 \mathrm{~m} / \mathrm{z})$ for precursor ion selection. The MS/MS spectra were accumulated for $60 \mathrm{~ms}$ in the $\mathrm{m} / \mathrm{z}$ $350-1500 \mathrm{~m} / \mathrm{z}$ range.

To extract SWATH peak areas with PeakView software 2.1, we carried out retention time calibration with endogenous peptides and data processing using following settings; 100 maximal peptides per protein, maximal 6 transitions per peptide, peptide confidence threshold of $99 \%$, transition false discovery rate $<1 \%$, 10 min extraction window, and fragment extraction tolerance of $75 \mathrm{ppm}$, exclusion of shared peptides. The protein peak areas were normalized to the total peak area and $\log$-transformed peak areas and subjected to Student's $t$-test to compare relative protein peak area between samples. Proteins were considered to be differentially expressed with $p<0.05$ and protein fold change was \pm 1.5 fold. DAVID $^{76}$ was used for functional enrichment analysis. The Benjamini method (adjusted $p$ value) was used to control the family-wide false discovery rate for enrichment analysis.

\section{Identification of SDHA-interacting proteins. Mitochondria isolated from} $\mathrm{SDHB}^{\mathrm{KO}}$ cell stably expressing SDHA-FLAG and empty vector were lysed using membrane solubilization buffer ( $1 \% n$-dodecyl $\beta$-D-maltoside, $20 \mathrm{mM}$ Tris- $\mathrm{HCl}$, pH 7.4, $0.1 \mathrm{mM}$ EDTA, $100 \mathrm{mM} \mathrm{NaCl}, 10 \%$ glycerol) supplemented with protease inhibitors (Roche). Protein concentrations were determined using the BCA protein assay kit. Equal amounts of protein were incubated with $20 \mu \mathrm{l}$ anti-FLAG M2 agarose beads (Sigma) overnight at $4{ }^{\circ} \mathrm{C}$. Beads were washed three times with the membrane solubilization buffer. The proteins bound to the beads were then eluted with $2 \times$ SDS lysis buffer and separated by $15 \%$ SDS-PAGE followed by silver staining (Mass spectrometry compatible, Life Technologies). Protein bands from control and treatment lanes were subjected to tryptic digest and analyzed by mass spectrometry.

\section{Sample preparation for NMR spectroscopy and LC-MS. Metabolites were} extracted from parental, $\mathrm{SDHB}^{\mathrm{KO}} \mathrm{EV}$, and $\mathrm{SDHB}^{\mathrm{KO}} \mathrm{SDHA}{ }^{\text {low }}$ cells $\left(3 \times 10^{6}\right.$ cells $)$ with $400 \mu \mathrm{l}$ of mixture composed of methanol, acetonitrile, and distilled water $(5: 3: 2)$. The samples were centrifuged at $15,000 \times g$ for $20 \mathrm{~min}$ at $4{ }^{\circ} \mathrm{C}$. The supernatant was collected, divided into two portions at the ratio of 1:5 for LC-MS and NMR analysis, and dried with a vacuum centrifuge (Vision). The pellets for LC-MS were dissolved with $30 \mu \mathrm{l}$ mixture of HPLC-grade acetonitrile and water (1:1), and those for NMR with $500 \mu \mathrm{l}$ buffer composed of $2 \mathrm{mM} \mathrm{Na}_{2} \mathrm{HPO}_{4}$ and $5 \mathrm{mM}$ $\mathrm{NaH}_{2} \mathrm{PO}_{4}$ in $\mathrm{D}_{2} \mathrm{O}$ with $0.025 \%$ TSP (trimethylsilylpropionic acid sodium salt- $\mathrm{D}_{4}$ ) as an internal standard. For the isotopologue distribution analysis, these cells were cultured in glucose and glutamine-free DMEM media (Gibco) supplemented with $10 \%$ dialyzed FBS (Welgene, Daegu, Korea), $10 \% \mathrm{D}_{2} \mathrm{O}, 5 \mathrm{mM}$ unlabeled glucose, and $20 \mathrm{mM} \mathrm{U}-{ }^{13} \mathrm{C}_{6}$-labeled glucose (Cambridge Isotope Laboratories) or $4 \mathrm{mM} \mathrm{U}$ ${ }^{13} \mathrm{C}_{5}$-labeled glutamine (Cambridge Isotope Laboratories) for $24 \mathrm{~h}$ before metabolites extraction, respectively.

Measurement and analysis for NMR spectroscopy and LC-MS. Untargeted metabolomic profiling was performed using NMR, and targeted profiling by LCMS multiple reaction monitoring for metabolites that are not readily discernible by NMR. Metabolites detected by both methods, such as succinate and glutamate, exhibited consistent results. 1D NMR spectra were obtained using a $500-\mathrm{MHz}$ Bruker Avance spectrometer equipped with a cryogenic triple resonance probe (KBSI). For the pulse program, 'noesygpprld' was used with 64 scans, and the final spectra were constructed to $16 \mathrm{~K}$ points. The metabolites were identified with Chenomx spectral database (Edmonton, Alberta, Canada) and comparison with standard compounds ${ }^{39}$. LC-MS data were obtained with an LTQ XL high performance linear ion trap mass spectrometer (Thermo Fisher Scientific) equipped with an electrospray ionization source. The operating conditions of the mass spectrometer were as follows: $5 \mathrm{kV}$ of ion spray voltage, heated capillary temperature of $275^{\circ} \mathrm{C}$, and sheath gas (nitrogen), auxiliary gas (nitrogen), and sweep gas (nitrogen) pressures of 35,10 , and 2 (arbitrary units), respectively. Full scanning analyses were performed in the range of $m / z$ 85-1000, and a 35-V normalized collision energy was used for MS/MS. Mobile phases were $10 \mathrm{mM}$ ammonium carbonate ( $\mathrm{pH}$ 9.1) in distilled water (A) and acetonitrile (B), and the flowrate was $0.15 \mathrm{ml} / \mathrm{min}$. The gradient scheme was as follows: $80 \% \mathrm{~B}$ at $0 \mathrm{~min}, 35 \% \mathrm{~B}$ at $10 \mathrm{~min}$, $5 \% \mathrm{~B}$ at $12 \mathrm{~min}, 5 \% \mathrm{~B}$ at $25 \mathrm{~min}, 80 \% \mathrm{~B}$ at $25.1 \mathrm{~min}$, and $80 \% \mathrm{~B}$ at $35 \mathrm{~min}$. The ZicpHilic Polymeric Beads Peek Column $(150 \times 2.1 \mathrm{~mm}, 5 \mu \mathrm{m}$; Merck $)$ was used at 35 ${ }^{\circ} \mathrm{C}$, and the autosampler temperature was set at $4{ }^{\circ} \mathrm{C}$. The peak areas of parental ion and its isotopologues were measured using Xcalibur (Thermo Fisher Scientific). The metabolites were identified by $\mathrm{m} / \mathrm{z}$ values and MS/MS fragmentation patterns from Human Metabolome Database (HMDB) and METLIN databases and also by comparison with standard compounds ${ }^{77}$. For multivariate analysis, the NMR data were Fourier-transformed, phase-corrected, and baseline-corrected manually using MestReNova (Mestrelab Research, Santiago de Compostela, Spain). The signal intensities were normalized against the intensity of the $0.025 \%$ TSP signal at $0 \mathrm{ppm}$ and total area values. The processed NMR data were saved into a text file and binned at a 0.004-ppm interval. The water region (4.66-5.0) was excluded from the spectra. The binning and normalization were performed using a Perl software written in-hous ${ }^{78}$. The region corresponding to water $(4.66-5.0 \mathrm{ppm})$ was removed from the spectra, and the data were imported into SIMCA-P software (Umetrics) for PLS-DA. The heat map was constructed with a relative $Z$-score of peak area of each metabolite identified by NMR and LC-MS.

RNA sequence analysis. RNA was isolated using RNAzol (Molecular Research Center) according to the manufacturer's instructions. RNA was dissolved in the TE buffer (Thermofisher), and remaining DNA contamination was removed using DNAse I (Sigma-Aldrich) for $30 \mathrm{~min}$. To clean RNA, the same volume of $8 \mathrm{M} \mathrm{LiCl}$ (Sigma-Aldrich) was added and incubated overnight at $-20^{\circ} \mathrm{C}$. Samples were centrifuged for $30 \mathrm{~min}$ at $16,100 \times \mathrm{g} / 2{ }^{\circ} \mathrm{C}$; the supernatant was removed and the pellet washed twice in $80 \%$ ethanol, followed by centrifugation as above. The remaining ethanol was evaporated at $65^{\circ} \mathrm{C}$ for $10 \mathrm{~min}$, and RNA was dissolved in $20 \mu \mathrm{l}$ of TE buffer. Total RNA concentration was measured by Nanodrop 2000, and its quality was assessed by the Fragment Analyzer (Advanced Analytical) using Standard Sensitivity RNA Analysis Kit (Advanced Analytical). The libraries were prepared from $2 \mu \mathrm{g}$ of total RNA using QuantSeq 3'mRNA-Seq Library Prep Kit FWD for Illumina (Lexogen), pooled and sequenced on MiSeq v3 kit in the $150 \mathrm{bp}$ SE mode.

About 2 million reads per sample were obtained, and low-quality reads were filtered out using TrimmomaticSE (v. $0.36^{79}$ ) with parameters "trimmomatic/ TRIM_MDA_K4_1_sequence.fastq CROP:165 HEADCROP:12 ILLUMINACLIP: /Lexogen_quantseq.fa:2:30:10 LEADING:3 TRAILING:3

SLIDINGWINDOW:4:15 MINLEN:36". Ribosomal and mitochondrial RNA reads were removed using Sortmerna $\left(\mathrm{v} 2.1 \mathrm{~b}^{80}\right)$ using default parameters. The remaining reads were aligned to the Human Genome Version GRCh38.87 and count tables were generated using STAR (v 2.5.2 ${ }^{81,82}$ ). Differentially expressed genes (DEGs) were analyzed by means of DESeq2 (v 1.18.0, ${ }^{82}$ ) using the default function "DESeq" without altered parameters. Result tables were generated as contrast between the $\mathrm{SDHB}^{\mathrm{KO}}$ and parental, $\mathrm{SDHB}^{\mathrm{KO}} \mathrm{SDHA}^{\mathrm{low}}$ and parental, and $\mathrm{SDHB}^{\mathrm{KO}}$ and $\mathrm{SDHB}^{\mathrm{KO}} \mathrm{SDHA}{ }^{\text {low }}$ cells. Genes with padj $<0.1$ for at least one pair of comparisons were chosen as DEGs. The function "plotPCA" from DESeq2 package with default parameters was used for PCA analysis. The heat-map was created from rlog transformed count data after subtraction of their mean values for every DEG. Altogether, we identified 523 significantly changed genes out of the total number of 7587 detected genes (DESeq2 BaseMean >5). The data have been deposited in NCBI's Gene Expression Omnibus and are accessible through GEO Series accession number GSE108938.

For gene set enrichment analysis, DEGs were filtered and used for clustering and ontology analysis. The normalized counts of these genes for all biological replicates and cell lines (parental-MDA231, $\mathrm{SDHB}^{\mathrm{KO}}-\mathrm{SHB}$, and $\mathrm{SDHB}^{\mathrm{KO}}$ SDHA ${ }^{\text {low }}-\mathrm{SH} 1$ ) were used to analyze for patterns of expression across the three cell lines. The data were first normalized across cell lines by dividing the mean of the replicates by the sum of the mean of the replicates. The R package optCluster ( $\mathrm{R}$ ver. 3.4.3) was then used to determine the best clustering algorithm among agnes, clara, diana, hierarchical, kmeans, pam, and sota clustering methods using the validation methods connectivity, Dunn index and silhouette width, and the number of clusters set to ten ${ }^{83}$. Clusters that showed similar expression profiles were then merged.

Gene ontology was performed on the genes from each unique cluster, using the $\mathrm{R}$ package gprofiler, to identify significantly $(p$-value $<0.05)$ enriched GO terms ${ }^{84}$. The genes were analyzed with no specified ranking while the gSCS (Set Counts and Sizes) algorithm was used to determine the significance threshold. All identified genes from the RNASeq were used as background. GO annotations inferred by in silico methods were included in the analysis. 
After the genes were linked to their appropriate GO terms, REVIGO was used to cluster similar GO terms together while using the $p$-value output from gprofiler to create a ranked list ${ }^{85}$. A similarity of 0.7 using the SimRel semantic similarity method was used to group similar GO terms and the UniProt database (15 March 2017) was used to find the relevant GO term sizes. Output from REVIGO was visualized as treemaps.

2D in-cell NMR analysis. Six plates of 70\% confluent cultured cells were harvested with centrifugation. After re-suspending the cells with $5 \mathrm{ml}$ DPBS, the cells were counted and $3 \times 10^{7}$ cells were transferred into a fresh tube. After centrifugation, the harvested cells were re-suspended in $500 \mu \mathrm{l}$ glucose-free DMEM media (Gibco) supplemented with $10 \%$ dialyzed FBS, $25 \mathrm{mM} \mathrm{U}-{ }^{13} \mathrm{C}_{6}$-labeled glucose, and $10 \%$ $\mathrm{D}_{2} \mathrm{O}$. The cells were spun in an NMR $(30 \mathrm{~g}, 100 \mathrm{~s})$ to allow sedimentation, enough to cover the active region of the NMR detection coil. ${ }^{1} \mathrm{H}^{13}{ }^{13} \mathrm{C}$ Heteronuclear Single Quantum Coherence (HSQC) NMR spectra were measured using the $800-\mathrm{MHz}$ Bruker Avance spectrometer equipped with a cryogenic triple resonance probe (Seoul National University). The dataset comprises $1024 \times 128$ points for direct and indirect dimensions, respectively. The time course spectral measurement was obtained at $310 \mathrm{~K}$ for 24 time points, with each experiment lasting for $288 \mathrm{~s} \mathrm{(13}$ points). Each metabolite was identified by spiking the standard compound.

Transmission electron microscopy. TEM was accomplished as follows. Cells were grown on cover-slips, fixed with $2 \%$ glutaraldehyde (Agar Scientific) and post-fixed with $1 \% \mathrm{OsO}_{4}$ made up in Sorensen's phosphate buffer $(0.1 \mathrm{M}, \mathrm{pH}$ 7.2-7.4), dehydrated, and embedded in Epon-Durkupan (Sigma-Aldrich). Ultrathin sections $(\sim 70-90 \mathrm{~nm})$ were cut, contrasted with uranyl acetate (Agar Scientific), and examined in the Morgagni 268 transmission electron microscope (FEI) at $80 \mathrm{kV}$ and in the TECNAI G2 20 LaB6 electron microscope (FEI) at $200 \mathrm{kV}$. Images were captured with Mega View III CCD camera (Olympus Soft Imaging Solutions).

Paraganglioma patients. Tumor tissue from 6 patients ( 3 with $S D H B$ mutations, 1 with SDHA mutation, 2 sporadic) was used in this study. Tumor tissue was obtained during surgery at the National Institutes of Health (NIH). Genetic testing was performed by NIH in collaboration with the Mayo Clinic (Rochester, MN, USA) or the results were sent from external facilities to the NIH. Expression of SDHB and SDHA proteins was also evaluated by immunohistochemistry as previously described ${ }^{86}$. Signed written consent was obtained from all patients prior to any experimental work. The use of patient samples was allowed by the Eunice Kennedy Shriver NICHD IRB (Ethics Approval \#00-CH-0093). The tumor samples examined were as follows (Sample code, affected subunit, DNA base pair change, protein amino acid change): S/ne7, SDHB, c.183T>G, p.Tyr61X; S-275, SDHB, c.526G > T, p.Glu17X; S-73, SDHB, c.268C >T, p.Arg90X; S-281 A/B, SDHA, c.91C $>$ T, p.Arg31X; S-187, Sporadic, no CII subunit affected; S-76, Sporadic, no CII subunit affected.

Statistical evaluation. Unless stated otherwise, data are mean values $\pm S D$ of at least three independent experiments. In mouse experiments, groups of 6 animal were used, unless stated otherwise. The two-tailed unpaired Student's $t$-test was used to assess statistical significance with $p<0.05$ being regarded as significant. Images are representative of three independent experiments.

Data availability. RNA sequence data are filed in NCBI's Gene Expression Omnibus and are accessible through GEO Series accession number GSE108938. The mass spectrometry proteomics data have been deposited to the ProteomeXchange Consortium via the PRIDE partner repository with the dataset identifier PXD009656. All other data that support findings of this study are available from the corresponding authors upon request.

Received: 3 September 2017 Accepted: 7 May 2018

Published online: 07 June 2018

\section{References}

1. Jones, R. G. \& Thompson, C. B. Tumor suppressors and cell metabolism: a recipe for cancer growth. Genes Dev. 23, 537-548 (2009).

2. King, A., Selak, M. A. \& Gottlieb, E. Succinate dehydrogenase and fumarate hydratase: linking mitochondrial dysfunction and cancer. Oncogene 25, 4675-4682 (2006).

3. Selak, M. A. et al. Succinate links TCA cycle dysfunction to oncogenesis by inhibiting HIF-alpha prolyl hydroxylase. Cancer Cell. 7, 77-85 (2005).

4. Bezawork-Geleta, A., Rohlena, J., Dong, L., Pacak, K. \& Neuzil, J. Mitochondrial Complex II: at the Crossroads. Trends Biochem. Sci. 42, 312-325 (2017).

5. Fendt, L. et al. Accumulation of mutations over the entire mitochondrial genome of breast cancer cells obtained by tissue microdissection. Breast Cancer Res. Treat. 128, 327-336 (2011)
6. Parrella, P. et al. Detection of mitochondrial DNA mutations in primary breast cancer and fine-needle aspirates. Cancer Res. 61, 7623-7626 (2001).

7. Tseng, L. M. et al. Mitochondrial DNA mutations and mitochondrial DNA depletion in breast cancer. Genes Chromosomes Cancer 45, 629-638 (2006).

8. Wallace, D. C. Mitochondria and cancer. Nat. Rev. Cancer 12, 685-698 (2012)

9. McKenzie, M., Lazarou, M., Thorburn, D. R. \& Ryan, M. T. Mitochondrial respiratory chain supercomplexes are destabilized in Barth Syndrome patients. J. Mol. Biol. 361, 462-469 (2006).

10. Lapuente-Brun, E. et al. Supercomplex assembly determines electron flux in the mitochondrial electron transport chain. Science 340, 1567-1570 (2013).

11. Acin-Perez, R., Fernandez-Silva, P., Peleato, M. L., Perez-Martos, A. \& Enriquez, J. A. Respiratory active mitochondrial supercomplexes. Mol. Cell 32, 529-539 (2008).

12. Kovarova, N. et al. High molecular weight forms of mammalian respiratory chain complex II. PLoS ONE 8, e71869 (2013).

13. Tan, A. S. et al. Mitochondrial genome acquisition restores respiratory function and tumorigenic potential of cancer cells without mitochondrial DNA. Cell Metab. 21, 81-94 (2015).

14. Plass, C. et al. Mutations in regulators of the epigenome and their connections to global chromatin patterns in cancer. Nat. Rev. Genet. 14, 765-780 (2013)

15. Maiuri, M. C. \& Kroemer, G. Essential role for oxidative phosphorylation in cancer progression. Cell Metab. 21, 11-12 (2015).

16. Leach, K. L. et al. The site of action of oxazolidinone antibiotics in living bacteria and in human mitochondria. Mol. Cell 26, 393-402 (2007).

17. Prezant, T. R. et al. Mitochondrial ribosomal RNA mutation associated with both antibiotic-induced and non-syndromic deafness. Nat. Genet. 4, 289-294 (1993).

18. Ramachandran, A. et al. Inhibition of mitochondrial protein synthesis results in increased endothelial cell susceptibility to nitric oxide-induced apoptosis. Proc. Natl Acad. Sci. USA 99, 6643-6648 (2002).

19. Maio, N. et al. Disease-causing SDHAF1 mutations impair transfer of Fe-S clusters to SDHB. Cell Metab. 23, 292-302 (2016).

20. van Nederveen, F. H. et al. An immunohistochemical procedure to detect patients with paraganglioma and phaeochromocytoma with germline SDHB, SDHC, or SDHD gene mutations: a retrospective and prospective analysis. Lancet Oncol. 10, 764-771 (2009).

21. Bezawork-Geleta, A., Saiyed, T., Dougan, D. A. \& Truscott, K. N. Mitochondrial matrix proteostasis is linked to hereditary paraganglioma: LON-mediated turnover of the human flavinylation factor SDH5 is regulated by its interaction with SDHA. FASEB J. 28, 1794-1804 (2014).

22. Sun, F. et al. Crystal structure of mitochondrial respiratory membrane protein complex II. Cell 121, 1043-1057 (2005)

23. Robinson, B. H., Petrova-Benedict, R., Buncic, J. R. \& Wallace, D. C. Nonviability of cells with oxidative defects in galactose medium: a screening test for affected patient fibroblasts. Biochem. Med. Metab. Biol. 48, 122-126 (1992).

24. Benard, G. \& Rossignol, R. Ultrastructure of the mitochondrion and its bearing on function and bioenergetics. Antioxid. Redox Signal. 10, 1313-1342 (2008).

25. Stroud, D. A., Formosa, L. E., Wijeyeratne, X. W., Nguyen, T. N. \& Ryan, M. T. Gene knockout using transcription activator-like effector nucleases (TALENs) reveals that human NDUFA9 protein is essential for stabilizing the junction between membrane and matrix arms of complex I. J. Biol. Chem. 288, 1685-1690 (2013)

26. Oostveen, F. G., Au, H. C., Meijer, P. J. \& Scheffler, I. E. A Chinese hamster mutant cell line with a defect in the integral membrane protein CII-3 of complex II of the mitochondrial electron transport chain. J. Biol. Chem. 270, 26104-26108 (1995)

27. Housley, S. L. et al. Renal carcinoma with giant mitochondria associated with germ-line mutation and somatic loss of the succinate dehydrogenase B gene. Histopathology 56, 405-408 (2010).

28. Rost, H. L. et al. OpenSWATH enables automated, targeted analysis of dataindependent acquisition MS data. Nat. Biotechnol. 32, 219-223 (2014).

29. Ghazalpour, A. et al. Comparative analysis of proteome and transcriptome variation in mouse. PLoS Genet. 7, e1001393 (2011).

30. Huang, S. et al. Complementary iTRAQ proteomics and RNA-seq transcriptomics reveal multiple levels of regulation in response to nitrogen starvation in Synechocystis sp. PCC 6803. Mol. Biosyst. 9, 2565-2574 (2013).

31. Cenik, C. et al. Integrative analysis of RNA, translation, and protein levels reveals distinct regulatory variation across humans. Genome Res. 25, 1610-1621 (2015)

32. Liu, Y., Beyer, A. \& Aebersold, R. On the dependency of cellular protein levels on mRNA abundance. Cell 165, 535-550 (2016).

33. Bauernfeind, A. L. \& Babbitt, C. C. The predictive nature of transcript expression levels on protein expression in adult human brain. BMC Genomics 18, 322 (2017).

34. Mitchell, A. D. \& Hoogenraad, N. J. De novo pyrimidine nucleotide biosynthesis in synchronized rat hepatoma (HTC) cells and mouse embryo fibroblast (3T3) cells. Exp. Cell Res. 93, 105-110 (1975). 
35. Sigoillot, F. D., Berkowski, J. A., Sigoillot, S. M., Kotsis, D. H. \& Guy, H. I. Cell cycle-dependent regulation of pyrimidine biosynthesis. J. Biol. Chem. 278, 3403-3409 (2003).

36. Lane, A. N. \& Fan, T. W. Regulation of mammalian nucleotide metabolism and biosynthesis. Nucleic Acids Res. 43, 2466-2485 (2015).

37. Vander Heiden, M. G., Cantley, L. C. \& Thompson, C. B. Understanding the Warburg effect: the metabolic requirements of cell proliferation. Science 324, 1029-1033 (2009).

38. Ackerman, D. \& Simon, M. C. Hypoxia, lipids, and cancer: surviving the harsh tumor microenvironment. Trends Cell Biol. 24, 472-478 (2014).

39. Wen, H., An, Y. J., Xu, W. J., Kang, K. W. \& Park, S. Real-time monitoring of cancer cell metabolism and effects of an anticancer agent using 2D in-cell NMR spectroscopy. Angew. Chem. Int. Ed. Engl. 54, 5374-5377 (2015).

40. Killian, J. K. et al. Succinate dehydrogenase mutation underlies global epigenomic divergence in gastrointestinal stromal tumor. Cancer Discov. 3, 648-657 (2013).

41. Kitazawa, S. et al. Succinate dehydrogenase B-deficient cancer cells are highly sensitive to bromodomain and extra-terminal inhibitors. Oncotarget $\mathbf{8}$, 28922-28938 (2017).

42. Letouze, E. et al. SDH mutations establish a hypermethylator phenotype in paraganglioma. Cancer Cell 23, 739-752 (2013).

43. Lussey-Lepoutre, C. et al. Loss of succinate dehydrogenase activity results in dependency on pyruvate carboxylation for cellular anabolism. Nat. Commun. 6, 8784 (2015).

44. Cardaci, S. et al. Pyruvate carboxylation enables growth of SDH-deficient cells by supporting aspartate biosynthesis. Nat. Cell Biol. 17, 1317-1326 (2015).

45. DeBerardinis, R. J. \& Chandel, N. S. Fundamentals of cancer metabolism. Sci. Adv. 2, e1600200 (2016).

46. Boroughs, L. K. \& DeBerardinis, R. J. Metabolic pathways promoting cancer cell survival and growth. Nat. Cell Biol. 17, 351-359 (2015)

47. Yang, C. et al. Glutamine oxidation maintains the TCA cycle and cell survival during impaired mitochondrial pyruvate transport. Mol. Cell 56, 414-424 (2014).

48. Mullen, A. R. et al. Reductive carboxylation supports growth in tumour cells with defective mitochondria. Nature 481, 385-388 (2011).

49. Lendvai, N. et al. Succinate-to-fumarate ratio as a new metabolic marker to detect the presence of SDHB/D-related paraganglioma: initial experimental and ex vivo findings. Endocrinology 155, 27-32 (2014).

50. Kluckova, K. et al. Ubiquinone-binding site mutagenesis reveals the role of mitochondrial complex II in cell death initiation. Cell Death Dis. 6, el749 (2015).

51. Cecchini, G. Function and structure of complex II of the respiratory chain. Annu. Rev. Biochem. 72, 77-109 (2003).

52. Hao, H. X. et al. SDH5, a gene required for flavination of succinate dehydrogenase, is mutated in paraganglioma. Science 325, 1139-1142 (2009).

53. Qi, W. et al. Pyruvate kinase M2 activation may protect against the progression of diabetic glomerular pathology and mitochondrial dysfunction. Nat. Med. 23, 753-762 (2017).

54. Ye, J. et al. Pyruvate kinase M2 promotes de novo serine synthesis to sustain mTORC1 activity and cell proliferation. Proc. Natl Acad. Sci. USA 109, 6904-6909 (2012).

55. Schulze, A. \& Harris, A. L. How cancer metabolism is tuned for proliferation and vulnerable to disruption. Nature 491, 364-373 (2012).

56. Christofk, H. R., Vander Heiden, M. G., Wu, N., Asara, J. M. \& Cantley, L. C. Pyruvate kinase M2 is a phosphotyrosine-binding protein. Nature 452, 181-186 (2008).

57. Bezawork-Geleta, A., Dong, L., Rohlena, J. \& Neuzil, J. The assembly factor SDHAF2 is dispensable for flavination of the catalytic subunit of mitochondrial complex II in breast cancer cells. J. Biol. Chem. 291, 21414-21420 (2016).

58. Brown, K. K., Spinelli, J. B., Asara, J. M. \& Toker, A. Adaptive reprogramming of De Novo pyrimidine synthesis is a metabolic vulnerability in triple-negative breast cancer. Cancer Discov. 7, 391-399 (2017).

59. Mathur, D. et al. PTEN regulates glutamine flux to pyrimidine synthesis and sensitivity to dihydroorotate dehydrogenase inhibition. Cancer Discov. 7, 380-390 (2017).

60. Rabinovich, S. et al. Diversion of aspartate in ASS1-deficient tumours fosters de novo pyrimidine synthesis. Nature 527, 379-383 (2015)

61. Zong, H. et al. AMP kinase is required for mitochondrial biogenesis in skeletal muscle in response to chronic energy deprivation. Proc. Natl Acad. Sci. USA 99, 15983-15987 (2002).

62. Hardie, D. G., Ross, F. A. \& Hawley, S. A. AMPK: a nutrient and energy sensor that maintains energy homeostasis. Nat. Rev. Mol. Cell Biol. 13, 251-262 (2012).

63. Canto, C. et al. AMPK regulates energy expenditure by modulating NAD +metabolism and SIRT1 activity. Nature 458, 1056-1060 (2009).

64. Guaras, A. et al. The $\mathrm{CoQH} 2 / \mathrm{CoQ}$ ratio serves as a sensor of respiratory chain efficiency. Cell Rep. 15, 197-209 (2016).

65. Benn, D. E. et al. Clinical presentation and penetrance of pheochromocytoma/ paraganglioma syndromes. J. Clin. Endocrinol. Metab. 91, 827-836 (2006).
66. Fishbein, L. et al. Comprehensive molecular characterization of pheochromocytoma and paraganglioma. Cancer Cell 31, 181-193 (2017).

67. Jochmanova, I. \& Pacak, K. Pheochromocytoma: the first metabolic endocrine cancer. Clin. Cancer Res. 22, 5001-5011 (2016).

68. Sancak, Y. et al. EMRE is an essential component of the mitochondrial calcium uniporter complex. Science 342, 1379-1382 (2013).

69. Blecha, J. et al. Antioxidant defense in quiescent cells determines selectivity of electron transport chain inhibition-induced cell death. Free Radic. Biol. Med. 112, 253-266 (2017).

70. Rohlenova, K. et al. Selective disruption of respiratory supercomplexes as a new strategy to suppress Her2high breast cancer. Antioxid. Redox Signal. 26, 84-103 (2017).

71. Vondrusova, M., Bezawork-Geleta, A., Sachaphibulkij, K., Truksa, J. \& Neuzil, J. The effect of mitochondrially targeted anticancer agents on mitochondrial (super)complexes. Methods Mol. Biol. 1265, 195-208 (2015).

72. Pasdar, E. A. et al. Characterisation of mesothelioma-initiating cells and their susceptibility to anti-cancer agents. PLoS ONE 10, e0119549 (2015)

73. Yan, B. et al. Mitochondrially targeted vitamin E succinate efficiently kills breast tumour-initiating cells in a complex II-dependent manner. $B M C$ Cancer 15, 401 (2015).

74. Dong, L. F. et al. Horizontal transfer of whole mitochondria restores tumorigenic potential in mitochondrial DNA-deficient cancer cells. Elife 6, 1-22 (2017).

75. Wu, J. X. et al. SWATH mass spectrometry performance using extended peptide MS/MS assay libraries. Mol. Cell. Proteom. 15, 2501-2514 (2016).

76. Huang da, W., Sherman, B. T. \& Lempicki, R. A. Bioinformatics enrichment tools: paths toward the comprehensive functional analysis of large gene lists. Nucleic Acids Res. 37, 1-13 (2009).

77. Wen, H. et al. Enhanced phase II detoxification contributes to beneficial effects of dietary restriction as revealed by multi-platform metabolomics studies. Mol. Cell. Proteomics 12, 575-586 (2013).

78. Wen, H. et al. A new NMR-based metabolomics approach for the diagnosis of biliary tract cancer. J. Hepatol. 52, 228-233 (2010).

79. Bolger, A. M., Lohse, M. \& Usadel, B. Trimmomatic: a flexible trimmer for Illumina sequence data. Bioinformatics 30, 2114-2120 (2014).

80. Kopylova, E., Noe, L. \& Touzet, H. SortMeRNA: fast and accurate filtering of ribosomal RNAs in metatranscriptomic data. Bioinformatics 28, 3211-3217 (2012).

81. Dobin, A. et al. STAR: ultrafast universal RNA-seq aligner. Bioinformatics 29 , (15-21 (2013)

82. Love, M. I., Huber, W. \& Anders, S. Moderated estimation of fold change and dispersion for RNA-seq data with DESeq2. Genome Biol. 15, 550 (2014).

83. Sekula, M., Datta, S. \& Datta, S. optCluster: an R Package for Determining the Optimal Clustering Algorithm. Bioinformation 13, 101-103 (2017).

84. Reimand, J. et al. g:Profiler-a web server for functional interpretation of gene lists (2016 update). Nucleic Acids Res. 44, W83-W89 (2016).

85. Supek, F., Bosnjak, M., Skunca, N. \& Smuc, T. REVIGO summarizes and visualizes long lists of gene ontology terms. PLoS ONE 6, e21800 (2011).

86. Papathomas, T. G. et al. SDHB/SDHA immunohistochemistry in pheochromocytomas and paragangliomas: a multicenter interobserver variation analysis using virtual microscopy: a Multinational Study of the European Network for the Study of Adrenal Tumors (ENS@T). Mod. Pathol. 28, 807-821 (2015)

\section{Acknowledgements}

The work was supported in part by the ARC Discovery grant, Czech Science Foundation (15-02203S) and Czech Health Foundation grant (17-30138A) to J.N., bilateral funding by the Czech Science Foundation and National Science Foundation of Korea (17-01192J/ NRF-2016K2A9A1A06921853) to J.N. and S.P., Czech Science Foundation grant (17 20904S and 16-22823S) to J.R., funding by Genesis Oncology Trust, the Cancer Society of New Zealand and the Health Research Council of New Zealand to M.V.B., the Basic Science Research Program (2009-83533), the Bio-Synergy Research Project (NRF2015M3A9C4075818) through the National Research Foundation of Korea funded by the Ministry of Education Science and Technology and Ministry of Science, ICT and Future Planning to S.P., by the Technology Agency of the Czech Republic (TE01020118) IMG grant (RVO: 68378050) to M.S. and P.H., and the institutional support of the Institute of Biotechnology RVO: 86652036, by the BIOCEV European Regional Development Fund CZ.1.05/1.100, and by the Intramural Research Program of the NIH, NICHD. H.W. was supported by the National Key Research and Development Program of China (2017YFA0503900) and Science and Technology Foundation of Shenzhen City (JCYJ20170302144650949). Proteomic analysis was facilitated by access to the Australian Proteome Analysis Facility supported in part by the Australian Government's National Collaborative Research Infrastructure Strategy. The electron microscopy data were produced at the Microscopy Centre-Electron Microscopy Core Facility (Institute of Molecular Genetics, Czech Academy of Sciences, Prague, Czech Republic) supported by Ministry of Education, Youth and Sports of the Czech Republic (LM2015062 CzechBioImaging). 


\section{Author contributions}

A.B.-G. and J.N. conceived the project and designed the study. A.B.-G. performed the majority of the experiments. H.W. and S.P. designed and performed metabolomics study and analyzed the data. V.C., Y.P., and K.P. provided patient data and samples, and they performed H\&E and ICH analysis. L.K., K.V., R.Z., S.M.N., and S.B. performed the respiration studies, WB, and SDHB re-expression. M.S. and P.H. performed TEM analysis. T.Z. and M.P.M. performed SWATH-MS and bioinformatics analysis. L.D., B.Y., J. V., J.R., S.Z., and M.V.B. contributed reagents, materials, analytical tools, technical support, and ideas. P.A., R.N., R.S., S.M.N., and M.K. performed RNA sequence analysis and interpreted the data. A.B.-G., J.R., and J.N. wrote the manuscript. All authors discussed the results and edited the manuscript.

\section{Additional information}

Supplementary Information accompanies this paper at https://doi.org/10.1038/s41467018-04603-z

Competing interests: The authors declare no competing interests.

Reprints and permission information is available online at http://npg.nature.com/ reprintsandpermissions/
Publisher's note: Springer Nature remains neutral with regard to jurisdictional claims in published maps and institutional affiliations.

\section{(c) (1)}

Open Access This article is licensed under a Creative Commons Attribution 4.0 International License, which permits use, sharing, adaptation, distribution and reproduction in any medium or format, as long as you give appropriate credit to the original author(s) and the source, provide a link to the Creative Commons license, and indicate if changes were made. The images or other third party material in this article are included in the article's Creative Commons license, unless indicated otherwise in a credit line to the material. If material is not included in the article's Creative Commons license and your intended use is not permitted by statutory regulation or exceeds the permitted use, you will need to obtain permission directly from the copyright holder. To view a copy of this license, visit http://creativecommons.org/ licenses/by/4.0/.

(C) The Author(s) 2018 